\title{
Report on FY 2020 Testing in Support of the Development and Extension of ASME Code Rules for Grade 91
}

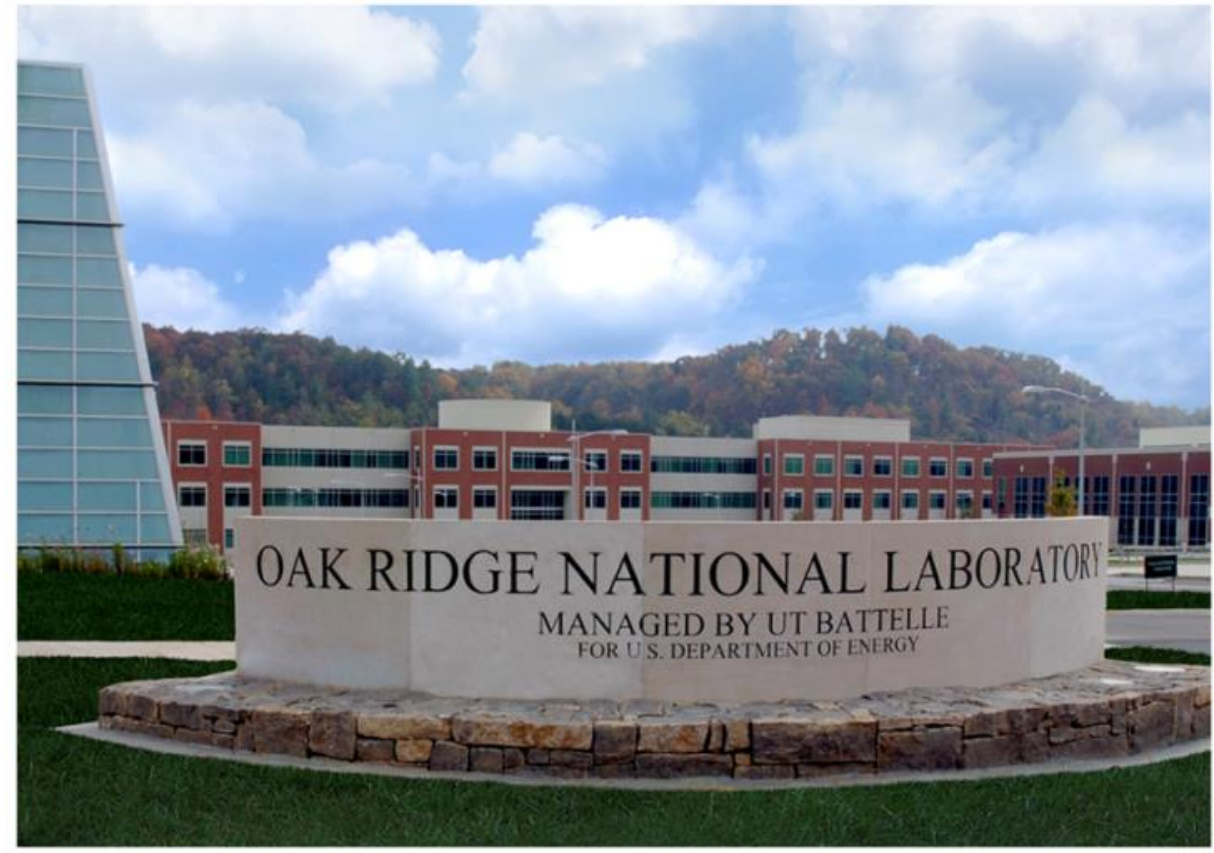

Yanli Wang Peijun Hou R. I. Jetter T.-L. Sham August 2020

Approved for public release. Distribution is unlimited. 


\title{
DOCUMENT AVAILABILITY
}

Reports produced after January 1, 1996, are generally available free via US Department of Energy (DOE) SciTech Connect.

Website www.osti.gov

Reports produced before January 1, 1996, may be purchased by members of the public from the following source:

\author{
National Technical Information Service \\ 5285 Port Royal Road \\ Springfield, VA 22161 \\ Telephone 703-605-6000 (1-800-553-6847) \\ TDD 703-487-4639 \\ Fax 703-605-6900 \\ E-mail info@ntis.gov \\ Website http://classic.ntis.gov/
}

Reports are available to DOE employees, DOE contractors, Energy Technology Data Exchange representatives, and International Nuclear Information System representatives from the following source:

Office of Scientific and Technical Information

PO Box 62

Oak Ridge, TN 37831

Telephone 865-576-8401

Fax 865-576-5728

E-mail reports@osti.gov

Website http://www.osti.gov/contact.html

This report was prepared as an account of work sponsored by an agency of the United States Government. Neither the United States Government nor any agency thereof, nor any of their employees, makes any warranty, express or implied, or assumes any legal liability or responsibility for the accuracy, completeness, or usefulness of any information, apparatus, product, or process disclosed, or represents that its use would not infringe privately owned rights. Reference herein to any specific commercial product, process, or service by trade name, trademark, manufacturer, or otherwise, does not necessarily constitute or imply its endorsement, recommendation, or favoring by the United States Government or any agency thereof. The views and opinions of authors expressed herein do not necessarily state or reflect those of the United States Government or any agency thereof. 


\title{
REPORT ON FY 2020 TESTING IN SUPPORT OF THE DEVELOPMENT AND EXTENSION OF ASME CODE RULES FOR GRADE 91
}

\author{
Yanli Wang \\ Peijun Hou* \\ R. I. Jetter** \\ T.-L. Sham ${ }^{\dagger}$
}

* University of Tennessee, Knoxville

${ }^{* *}$ R. I. Jetter Consulting

$\dagger$ Argonne National Laboratory

August 2020

Prepared by

OAK RIDGE NATIONAL LABORATORY

Oak Ridge, TN 37831-6283

managed by

UT-BATTELLE, LLC

for the

US DEPARTMENT OF ENERGY

under contract DE-AC05-00OR22725 



\section{CONTENTS}

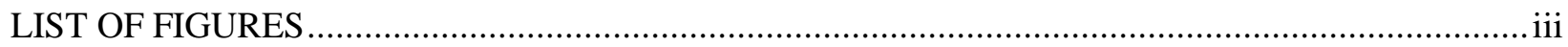

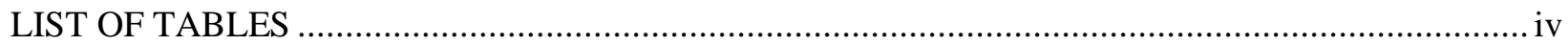

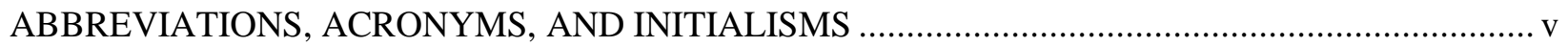

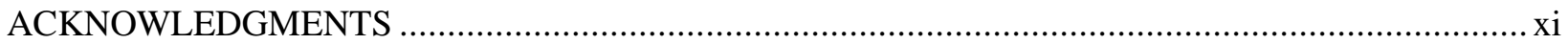

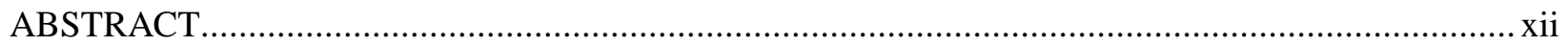

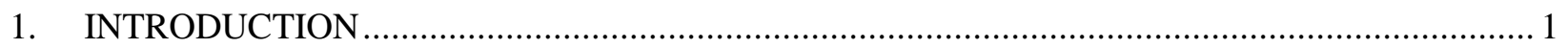

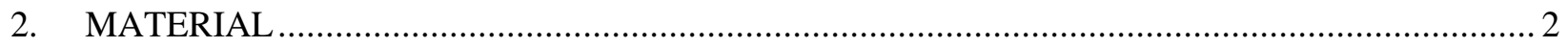

3. INCOPORATION OF TEMPERATURE-DEPENDEDNT FATIGUE CURVES FOR GR. 91

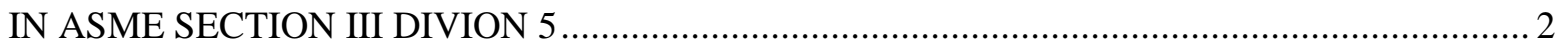

3.1 EVALUATION OF THE JSME DESIGN FATIGUE CURVES …................................ 2

3.1.1 JSME Gr. 91 Design Fatigue Curve Data Package and Data Storage ......................... 2

3.1.2 JSME Gr. 91 Best-Fit Fatigue Curves ................................................................... 3

3.2 EVALUATION OF MEAN STRESS CORRECTION ON THE FATIGUE DESIGN

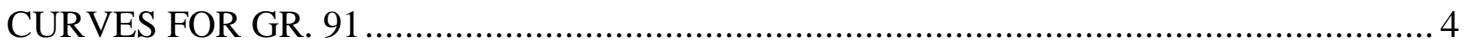

3.3 ASME TEMPERATURE-DEPENDENT DESIGN FATIGUE CURVES FOR GR. 91......... 4

4. PROGRESS IN DEVELOPMENT OF ALTERNATIVE CREEP-FATIGUE EVALUATION

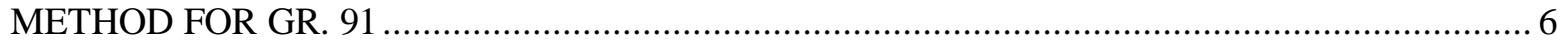

4.1 INTEGRATED EPP+SMT CF EVALUATION METHODOLOGY ............................... 6

4.2 SBSMT TEST RESULTS ON GR. 91 AT RELATIVELY LOW STRAIN RANGE.............. 7

4.3 EFFECT OF HOLD TIME ON SMT CREEP-FATIGUE LIFE ...................................... 11

4.3.1 Estimation of the Hold-Time Effect on Creep-Fatigue Cyclic Life........................... 11

4.3.2 Testing to Evaluate Hold-Time Effect on Gr. 91 at Low Strain Ranges.................... 13

4.3.3 SBSMT Hold-Time Testing with Large Elastic Follow-up Factor............................. 14

4.4 EVALUATION OF PRIMARY LOAD EFFECT ON SMT CF LIFE FOR GR. 91 .............. 15

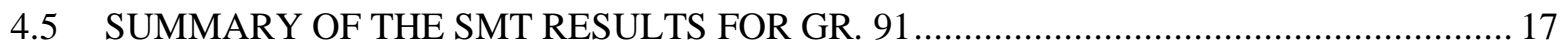

5. ADDITIONAL TESTING IN SUPPORT OF VERIFICATION OF GR. 91 CODE RULES........... 17

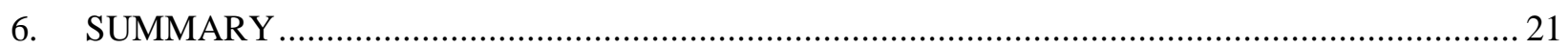

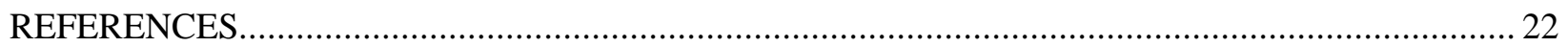




\section{LIST OF FIGURES}

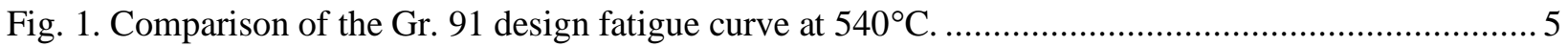

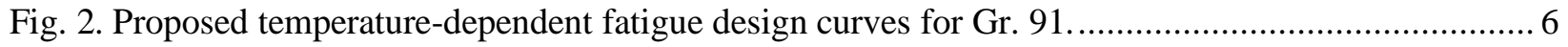

Fig. 3. Standard ASTM CF specimen geometry. Units are in millimeter............................................. 7

Fig. 4. Elastic follow-up factor as a function of applied cycle for Gr. 91 Gr. 91 SBSMT SB19 ............... 8

Fig. 5. Evolution of (a) strain range and (b) maximum and minimum stresses as a function of applied cycles, and (c) representative hysteresis loops for Gr. 91 SBSMT SB19..................... 8

Fig. 6. Stress relaxation behavior during compression holding segment. (a) Stress relaxation curves of representative cycles, (b) saturation stress, and (c) stress relaxation ratio for Gr.

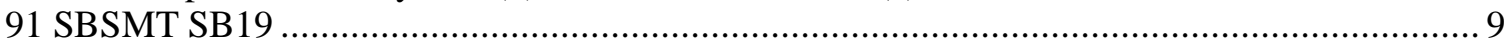

Fig. 7. Characteristics of the hysteresis loop of the SBSMT test. ..................................................... 10

Fig. 8. Evolution of (a) loading strain range and (b) creep strain as a function of applied cycles for SB19.

Fig. 9. Standard fatigue and creep-fatigue data and modified Coffin model for Gr. 91 at $600{ }^{\circ} \mathrm{C}$ with (a) $q=1.0$, (b) $q=2.0$, (c) $q=3.5$ and (d) predicted short hold-time effect

Fig. 10. Strain-controlled pure fatigue test on Gr. 91 at $600^{\circ} \mathrm{C}$ with (a) maximum and minimum stresses and (b) stress range as a function of applied cycles.

Fig. 11. Comparison of the strain-controlled fatigue test result with literature data and the JSME best-fit curve of $\mathrm{Gr} .91$ at $600^{\circ} \mathrm{C}$.

Fig. 12. Stress ranges and strain ranges as a function of applied cycles for SBSMT on Gr. 91 at $650^{\circ} \mathrm{C}$ with an elastic follow-up factor of 12 , with (a, d) compression hold of $600 \mathrm{~s},(\mathrm{~b}, \mathrm{e})$ tension hold of $180 \mathrm{~s}$, and (c, f) compression hold of $180 \mathrm{~s}$

Fig. 13. Tubular SBSMT specimen geometry. Units are in inches.

Fig. 14. Picture of the SBSMT specimen for evaluation of primary load effect.....

Fig. 15. Specimen design for creep testing with internal pressure and external axial compression loading.....

Fig. 16. Specimen design for creep testing with internal pressure and external axial tension loading.

Fig. 17. Compression fixtures for loading in conventional creep frames. .......................................... 20

Fig. 18. Gr. 91 specimens for multi-axial stress creep testing. 


\section{LIST OF TABLES}

Table 1. Chemical compositions of Gr. 91 plate with heat number 30176 (weight \%)......................... 2

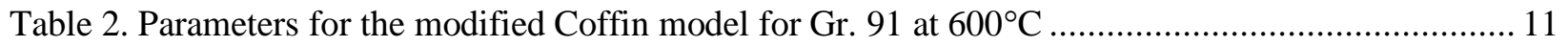

Table 3. Estimation of fatigue and $\mathrm{CF}$ life and test duration using modified Coffin model for Gr.

91 at $0.3 \%$ strain range at $600^{\circ} \mathrm{C}$.

Table 4. Testing parameters for evaluation of hold-time effect for Gr. 91 with an elastic follow-up factor of 1 13

Table 5. Summary of SMT CF results on Gr. 91 at $650^{\circ} \mathrm{C}$ (heat 30176). 17

Table 6. Designed stress state with effective von-Mises stress of $80 \mathrm{MPa}(11.6 \mathrm{ksi})$ 18 


\section{ABBREVIATIONS, ACRONYMS, AND INITIALISMS}

$\begin{array}{ll}\text { ART } & \text { Advanced Reactor Technologies } \\ \text { ANL } & \text { Argonne National Laboratory } \\ \text { ASME } & \text { American Society of Mechanical Engineers } \\ \text { B\&PV } & \text { Boiler and Pressure Vessel } \\ \text { CF } & \text { Creep-Fatigue } \\ \text { DOE } & \text { Department of Energy } \\ \text { EPP } & \text { elastic-perfectly plastic } \\ \text { Gr. } 91 & \text { modified Grade 91 Steel (9Cr-1Mo-V Steel) } \\ \text { ORNL } & \text { Oak Ridge National Laboratory } \\ \text { SMT } & \text { Simplified Model Test } \\ \text { TBSMT } & \text { two-bar SMT } \\ \text { SBSMT } & \text { single-bar SMT } \\ \text { WH-CFNC } & \text { Working Group-Creep-Fatigue and Negligible Creep }\end{array}$




\section{ACKNOWLEDGMENTS}

This research was sponsored by the US Department of Energy (DOE), Office of Nuclear Energy (NE), under contract DE-AC05-00OR22725 with Oak Ridge National Laboratory (ORNL), managed and operated by UT-Battelle LLC, and under contract No. DE-AC02-06CH11357 with Argonne National Laboratory, managed and operated by UChicago Argonne LLC. Programmatic direction was provided by the Office of Nuclear Reactor Deployment of DOE-NE.

The authors gratefully acknowledge the support provided by Tom Sowinski, DOE-NE, Federal Manager, Microreactor Program; Sue Lesica, DOE-NE, Federal Manager, Advanced Materials, Advanced Reactor Technologies Program; and Jess Gehin, Idaho National Laboratory, National Technical Director, Microreactor Program.

The authors also wish to thank ORNL staff members C. Shane Hawkins and Jeremy L. Moser for technical support and Lianshan Lin and Edgar Lara-Curzio for reviewing this report. 


\begin{abstract}
This report summarizes the FY 2020 research and activities at Oak Ridge National Laboratory in support of the ASME code rule development and code extension for Grade 91 (Gr. 91) steel. Incorporation of the Gr. 91 temperature-dependent fatigue curves in Section III Division 5 was one major task, and the associated major aspects brought up during the course of the ASME balloting process are documented in this report. Experiments and analysis continued on the development of the alternative creep-fatigue evaluation based on elastic-perfectly plastic (EPP) plus simplified model test (SMT) methodology. The focus of the study in FY 2020 was the evaluation of the hold-time effect at high cycle and low strain range region. Baseline testing in support of the evaluation of hold time effects was started and will continue in FY 2021. Major on-going experiments and activities in support of the ASME code development and extension of Gr. 91 will be completed in FY 2021.
\end{abstract}





\section{INTRODUCTION}

Grade 91 (Gr. 91) steel is currently an approved material for Class A construction in ASME Section III Division 5, Subsection HB, Subpart B (ASME 2019). To support the Microreactor program, integrated research and development activities by Argonne National Laboratory (Argonne) and Oak Ridge National Laboratory (ORNL) are conducted to develop and extend design rules to enable the use of Gr. 91 as a Class A construction material for core block design.

In FY 2020, qualification of Gr. 91 for elastic-perfectly plastic (EPP) strain limits and creep-fatigue (CF) evaluations led by ANL collaborators was completed. The qualification of EPP methods for Gr. 91 steel has technical significance because currently this steel is the only approved material for Division 5 Class A construction that is strongly cyclic softening. In FY 2020, research on Gr. 91 at ORNL mainly involved two aspects, incorporation of the temperature-dependent fatigue curves into ASME Boiler and Pressure Vessel (B\&PV) Code Section III, Division 5, Subsection HB, Subpart B; and research in support of the development of an alternative $\mathrm{CF}$ design methodology.

The current Code Section III, Division 5, Subsection HB, Subpart B has only one design fatigue curve for Gr. 91 at $540^{\circ} \mathrm{C}$ (or $1000^{\circ} \mathrm{F}$ ). The ASME Section III Working Group-Creep-Fatigue and Negligible Creep (WG-CFNC) has taken action to incorporate the temperature-dependent fatigue curves for Gr. 91 in Division 5. This report documents the major progress on this item through the ASME balloting process and the major aspects regarding the fatigue design curves. The temperature-dependent fatigue design curves for Gr. 91 are expected to be incorporated in the 2021 edition of the ASME code.

The current ASME code rules for CF evaluation based on the damage diagram require the separate evaluation of creep damage and fatigue damage. The uncertainties in the separate evaluation of creep damage and fatigue damage from the test data lead to the use of overly conservative design factors in the current $\mathrm{CF}$ procedure. The difficulty in the current damage diagram $\mathrm{CF}$ evaluation approach has led to the development of an alternative CF evaluation methodology, i.e., integrated EPP analysis and Simplified Model Test (SMT) methodology. The goal of this integrated EPP+SMT methodology is to maximize the advantages of both EPP methods and the SMT CF evaluation approach. The development of an SMTbased design curve requires a significant amount of SMT test data. Experimentally, SMT key feature CF testing has been successfully developed and tested for Alloy 617, SS 316H, SS 304H, and Gr. 91 (Wang et al. 2013, 2014, 2015, 2016a, 2016b, 2017a, 2017b). However, testing with the key feature SMT specimens poses challenges in that it requires specialized and costly instrumentation; and it is difficult to extract information to support the modeling and analysis. Major effort was invested in FY 2018 to develop improved testing methods to allow easier SMT-based CF testing. The improved techniques enable the use of standard CF specimens and significantly simplify the testing program. The new techniques were successfully verified in Wang et al. 2018a, 2018b, 2019a, 2019b, 2019c. In FY 2020, analysis was performed to evaluate the hold time effect on the SMT CF life. Lack of experimental data at the low strain range and high cycle region due to the long test duration to generate failure data has resulted in major uncertainties in extending the SMT-based design curves to the high cycle region. To address this issue, experiments were designed and are being performed at ORNL to support the extension of the integrated EPP-SMT design method to Gr. 91.

Major on-going experiments and activities in support of ASME code development and extension of Gr. 91 will be completed in FY 2021, with a few exceptions for long-term testing. 


\section{MATERIAL}

The Gr. 91 material used in this report was from the Gr. 91 plate with heat number 30176. It was manufactured by Carpenter Technology Corporation in the early 1980s, and it has been preserved at ORNL as an archival material. ORNL technical report ORNL-6303 (DiStefano et al. 1985) documented the chemical composition of this plate, which is listed in Table 1 below. Note that the silicon content is $0.11 \%$, which is lower than the ASME SA-387 specification of $0.2-0.5 \%$. This plate was characterized for its mechanical properties and the data were used as reference data for the Gr. 91 development program.

Table 1. Chemical compositions of Gr. 91 plate with heat number 30176 (weight \%).

\begin{tabular}{c|c|c|c|c|c|c|c|c|c|c}
\hline $\mathbf{C}$ & $\mathbf{P}$ & $\mathbf{S i}$ & $\mathbf{N i}$ & $\mathbf{M n}$ & $\mathbf{N}$ & $\mathbf{T i}$ & $\mathbf{S n}$ & $\mathbf{V}$ & $\mathbf{F e}$ & $\mathbf{A s}$ \\
\hline 0.081 & 0.010 & 0.11 & 0.09 & 0.37 & 0.055 & 0.004 & $<0.001$ & 0.209 & balance & 0.001 \\
\hline $\mathbf{Z r}$ & $\mathbf{S}$ & $\mathbf{C r}$ & $\mathbf{C o}$ & $\mathbf{M o}$ & $\mathbf{A l}$ & $\mathbf{W}$ & $\mathbf{C u}$ & $\mathbf{N b}$ & $\mathbf{B}$ & \\
\hline$<0.001$ & 0.003 & 8.61 & 0.010 & 0.89 & 0.007 & $<0.01$ & 0.04 & 0.072 & $<\mathbf{0 . 0 9}$ & \\
\hline
\end{tabular}

*Note: heat 30176 is low in Si content.

The as-received Gr. 91 plate was hot forged followed by hot rolling. The nominal thickness of the plate was $25.4 \mathrm{~mm}$ (or $1 \mathrm{in}$.). The plate material was heat treated to support this study. It was normalized at $1050^{\circ} \mathrm{C}$ for $1 \mathrm{~h}$ and then tempered at $760^{\circ} \mathrm{C}$ for $2 \mathrm{~h}$, followed by air cooling. The heat treatment was performed by Bodycote Thermal Processing Inc. in Morristown, Tennessee. The heat-treated Gr. 91 microstructure and room temperature properties satisfied ASME specification SA-387. All the specimens used in this study were machined along the plate rolling direction.

\section{INCOPORATION OF TEMPERATURE-DEPENDEDNT FATIGUE CURVES FOR GR. 91 IN ASME SECTION III DIVION 5}

The current ASME B\&PV Code Section III Division 5, Subsection HB, Subpart B has only one design fatigue curve for Gr. 91 at $540^{\circ} \mathrm{C}$ (or $1000^{\circ} \mathrm{F}$ ). Since fatigue design curves at higher temperatures are more limiting, there is not sufficient design information for Gr. 91 components operating at temperatures higher than $540^{\circ} \mathrm{C}$. The ASME Section III WG-CFNC has taken action and established the record number $15-2731$ to incorporate the temperature-dependent fatigue curves up to $649^{\circ} \mathrm{C}\left(1200^{\circ} \mathrm{F}\right)$ for $\mathrm{Gr}$. 91 based on data from the Japan Society of Mechanical Engineers (JSME). Incorporation of the temperaturedependent fatigue curves in ASME code will greatly enhance design flexibility for Gr. 91 as Class A elevated temperature service construction.

This section documents the incorporation of the Gr. 91 temperature-dependent fatigue curves in Division 5 and the associated major aspects brought up during the course of the ASME balloting process. The information reported here was included in the background documents for record 15-2731. At the time of writing this report, this proposal was approved by the Section III Standards Committee and in the process of procedural approval by the Board on Nuclear Codes and Standards. The temperature-dependent fatigue design curves for Gr. 91 are expected to be incorporated in the 2021 edition of the ASME code.

\subsection{EVALUATION OF THE JSME DESIGN FATIGUE CURVES}

\subsubsection{JSME Gr. 91 Design Fatigue Curve Data Package and Data Storage}

The temperature-dependent fatigue curves in the JSME Codes for Nuclear Power Generation FacilitiesRules on Design and Construction for Nuclear Power Plants were established in 2012 (JSME 2016). The 
technical background of the best-fit curves in the JSME Fast Reactor Code is summarized by Onizawa et al., 2013. Seven lots of Gr. 91 in plate form and seven lots in forging form were used to support the JSME codification. The chemical composition, heat treatment and room temperature tensile properties satisfy ASME B\&PV Code Section II SA-182M F91 and 387M 91 (Onizawa et al., 2013). Total fatigue data points are 305 , ranging from room temperature to $650^{\circ} \mathrm{C}$ ( or $1200^{\circ} \mathrm{F}$ ). The strain rate is from $1 \mathrm{E}-6 / \mathrm{s}$ to $1 \mathrm{E}-3 / \mathrm{s}$.

The database of the JSME Gr. 91 fatigue design curves is stored by the Japan Atomic Energy Agency (JAEA); however, the ownership of most of the data lies with the consortium of electrical companies, and the original data are not open to the public. JAEA-Data-Code-2008-030 (in Japanese) has documented the fatigue failure cycles and is available to the public. Additional information regarding the test data used in developing Gr. 91 design fatigue curves is available in the literature (Onizawa et al., 2013, Wang et al., 2019b, Wang et al., 2020). ASME Code committees consider the form of the background documents on the supporting data for record 15-2731 to be acceptable.

\subsubsection{JSME Gr.91 Best-Fit Fatigue Curves}

The JSME best-fit curve for fatigue life was analyzed by the Diercks method (Diercks et al., 1976). Fatigue curves developed by the Diercks method are expressed as a function of temperature, strain rate, and strain range. The equation of the best-fit curves for Gr. 91 fatigue life is given as in Onizawa et al. (2013)

$$
\left(\log _{10}^{N_{f}}\right)^{-\frac{1}{2}}=\left(A_{0}+A_{1} \cdot \log _{10} \varepsilon_{t}+A_{2} \cdot\left(\log _{10} \varepsilon_{t}\right)^{2}+A_{3} \cdot\left(\log _{10} \varepsilon_{t}\right)^{4}\right)
$$

where the parameters are defined as:

$A_{0}=1.182614-8.971940 \times 10^{-10} \times T^{2} \times R^{3}$

$A_{1}=6.379346 \times 10^{-1}-3.220658 \times 10^{-3} \times R$

$A_{2}=2.065574 \times 10^{-1}+3.103560 \times 10^{-11} \times T^{3}$

$A_{3}=-1.168810 \times 10^{-2}$

$R=\log _{10}(\dot{\varepsilon})$

$T:$ Temperature in degree $C$ for S.I.Units

$\varepsilon_{t}:$ Design fatigue strain range (in./in.or $\mathrm{m} / \mathrm{m}$ )

$\dot{\varepsilon}:$ Strain rate in $/$ in $/ \mathrm{s}$ or $\mathrm{m} / \mathrm{m} / \mathrm{s}$ )

The JSME best-fit temperature dependent fatigue curves for strain rates of 1E-3/s or higher were compared with the data of Ando of JAEA (Ando 2018). The best-fit curves represent the test data well.

The original JSME best-fit fatigue life equation was developed with the intent to cover up to 1E6 cycles in the design curves. The design fatigue curves proposed to ASME cover up to 1E8 cycles. The JSME best-fit fatigue life equation was extrapolated to up to $1 \mathrm{E} 8$ cycles. Because of the long-duration testing time for high numbers of cycles, there are limited test data available. Three fatigue data points with fatigue lives longer than 1E6 were used to validate this extrapolation. One data point was for a $0.20 \%$ strain range with cycles to failure of $6,772,955$ at $600^{\circ} \mathrm{C}$, one at $0.25 \%$ strain range with cycles to failure of $3,558,742$ at $550^{\circ} \mathrm{C}$ and a third one for a $0.20 \%$ strain range with cycles to failure of $21,091,549$ at $550^{\circ} \mathrm{C}$ (JAEA 2009). The fatigue curves generated by Eq.(1) coincide well with these test data, therefore, the extrapolation was justified as being reasonable. 


\subsection{EVALUATION OF MEAN STRESS CORRECTION ON THE FATIGUE DESIGN CURVES FOR GR. 91}

During the process of incorporating the Gr. 91 fatigue design curves, an issue regarding the effect of mean stresses on fatigue analysis, and how to consider the mean stress effect for elevated-temperature design, was brought up and discussed. High-temperate components under cyclic loading may experience mean stress effects. Mean stress can be categorized as either load-controlled or strain-controlled quantities. For load-controlled mean stress, such as that introduced by internal pressure, current CF design procedures (elastic or inelastic analysis route) account for creep damage introduced by sustained loading. Thus, the mean stress effect due to sustained primary loads shows up in the calculation of the life fraction used to enter the damage interaction diagram (Figure HBB-T-1420-2 in ASME Section III Division 5, "Creep-Fatigue Damage Envelope"). On the other hand, the effect of mean stress under strain-controlled cycling is introduced by a non-zero mean strain. Mean stress under strain-controlled cyclic loading corresponds to cases such as welding residual stress or residual stress by thermal transients. With concurrence from WG-CFNC members, ORNL performed strain-controlled fatigue tests for mean stress evaluation in accordance with the recommended test procedure by Section III Sub Working GroupFatigue Strength, "Recommended Test Procedure for Fatigue Testing of Metallic Materials below the Creep Range (ASME 1994). Note that this recommended procedure was originally developed for lightwater-reactor applications, and it was extended to high temperature applications in this study. Tests with and without mean strain were performed under strain-controlled cyclic loading at temperatures of $540^{\circ} \mathrm{C}$ $\left(1000^{\circ} \mathrm{F}\right)$ and $371^{\circ} \mathrm{C}\left(700^{\circ} \mathrm{F}\right)$. The details of the mean stress evaluation study were reported by Wang et al. 2019b, 2020.

The evaluation compared the fatigue life under standard strain-controlled fatigue testing with zero initial mean stress, with that under fatigue testing with non-zero initial mean stress introduced by pre-straining. Both tests were cyclically loaded at the same strain range, strain rate, and temperature. The four tests were carried out until the failure criteria were met. The results show that at both temperatures, the mean stresses introduced by pre-straining could not be maintained and decreased quickly as applied strain cycles were increased. At $540^{\circ} \mathrm{C}$, the test with pre-straining and non-zero initial mean stress had longer cyclic life than the test with standard fatigue and zero initial mean stress, indicating that mean stress correction is not needed at this temperature; at $371{ }^{\circ} \mathrm{C}$, the non-zero mean stress fatigue test showed slightly shorter cyclic life than that with standard fatigue, but the difference in fatigue life was small and well within the data scatter for fatigue testing. The ORNL test data demonstrate a negligible effect of applied mean strain on strain-controlled fatigue life; i.e., strain-controlled cycling with non-zero mean strain did not reduce the cycle life compared with cycling with zero mean strain. Therefore, mean stress correction is not recommended for the fatigue design curves in Division 5 for Gr. 91.

\subsection{ASME TEMPERATURE-DEPENDENT DESIGN FATIGUE CURVES FOR GR. 91}

The proposed ASME fatigue design curves are based on a cyclic fatigue testing strain rate of $1 \mathrm{E}-3 / \mathrm{s}$, so the fatigue life at a very slow strain rate due to the creep effect at high temperatures does not enter into these fatigue curves. At a strain rate of $1 \mathrm{E}-3 / \mathrm{s}$, the parameters in Eq. (1) become:

$$
\begin{aligned}
& R=-3 \\
& A_{0}=1.182614+2.422424 \times 10^{-8} \times T^{2} \\
& A_{1}=6.475966 \times 10^{-1} \\
& A_{2}=2.065574 \times 10^{-1}+3.103560 \times 10^{-11} \times T^{3} \\
& A_{3}=-1.168810 \times 10^{-2}
\end{aligned}
$$

The ASME fatigue design curves are generated by applying design factors of 2 on strain range and 20 on number of cycles to failure, and the lesser of these two gives the design allowable strain range at cycle. 
Unlike the JSME design curves, there was no smoothing between the intersection of the two curves in this proposal.

For the temperature range from room temperature to $371^{\circ} \mathrm{C}$ (or $700^{\circ} \mathrm{F}$ ), the curve for $371^{\circ} \mathrm{C}$ (or $700^{\circ} \mathrm{F}$ ) is used. The fatigue design curve at $540^{\circ} \mathrm{C}$ was compared with the existing curve in Figure HBB-T-1420-1E in Division 5, and the results are plotted in Fig. 1. The proposed new fatigue design curve matched the existing curve reasonably well.

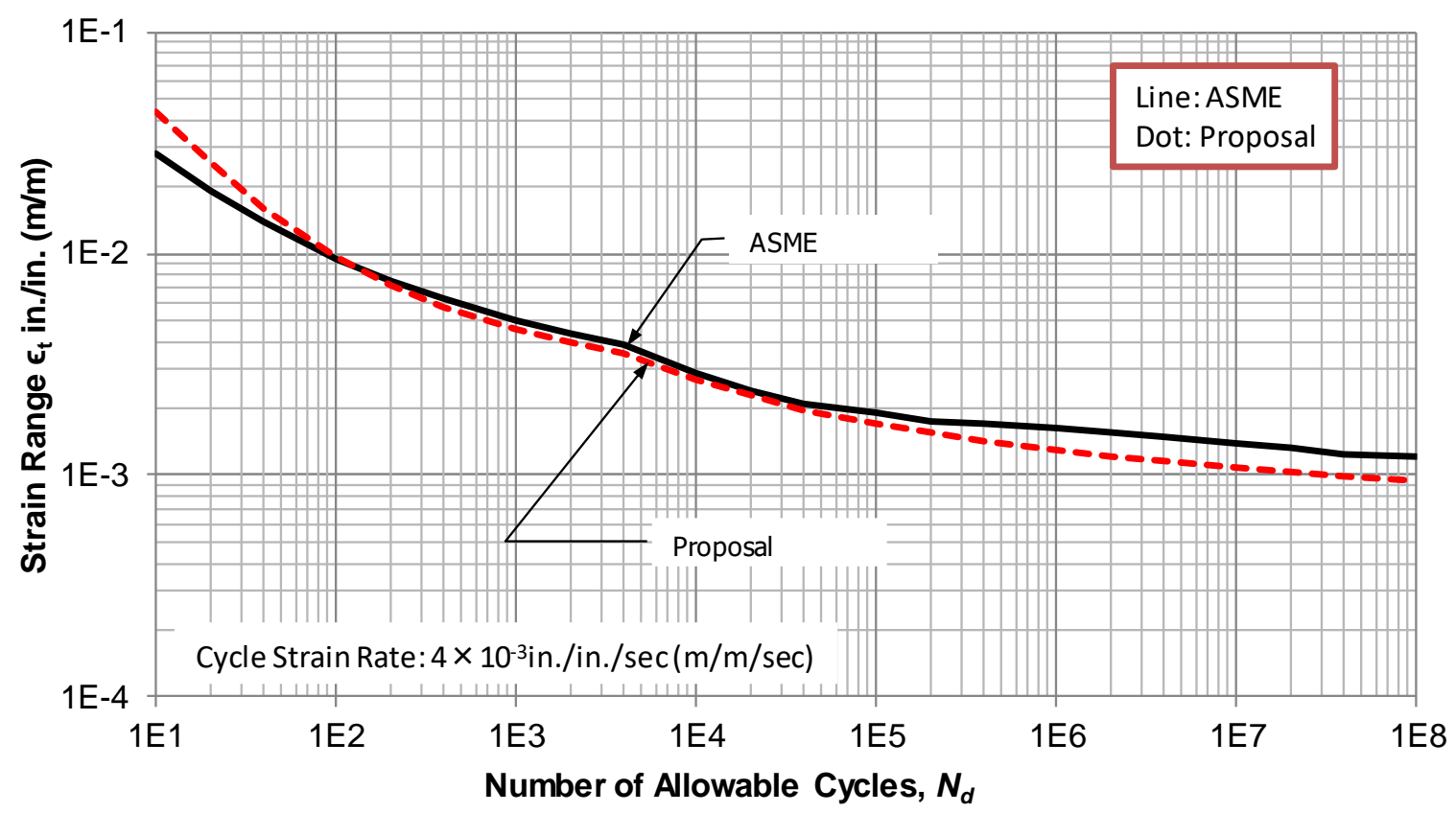

Fig. 1. Comparison of the Gr. 91 design fatigue curve at $540^{\circ} \mathrm{C}$.

The proposed temperature dependent design fatigue curves for ASME B\&PV Code Section III Subsection HB Subpart B are plotted in Fig. 2. Tabulated values for both US customary units and SI units are provided with the proposed curves. Note also that all the original calculations were done in SI units because the JSME equation was established on the basis of SI units. For U. S. customary units, the only change needed was the temperature conversion between degrees Celsius and degrees Fahrenheit, because the strain range and strain rate were the same for both units. The tabulated numerical values had 5 significant figures to ensure that the maximum error of $\left(\mathrm{Nd}-\mathrm{Nd} \_\mathrm{cal}\right) / \mathrm{Nd}$ based on the tabulated strain range values was less than $0.1 \%$. 


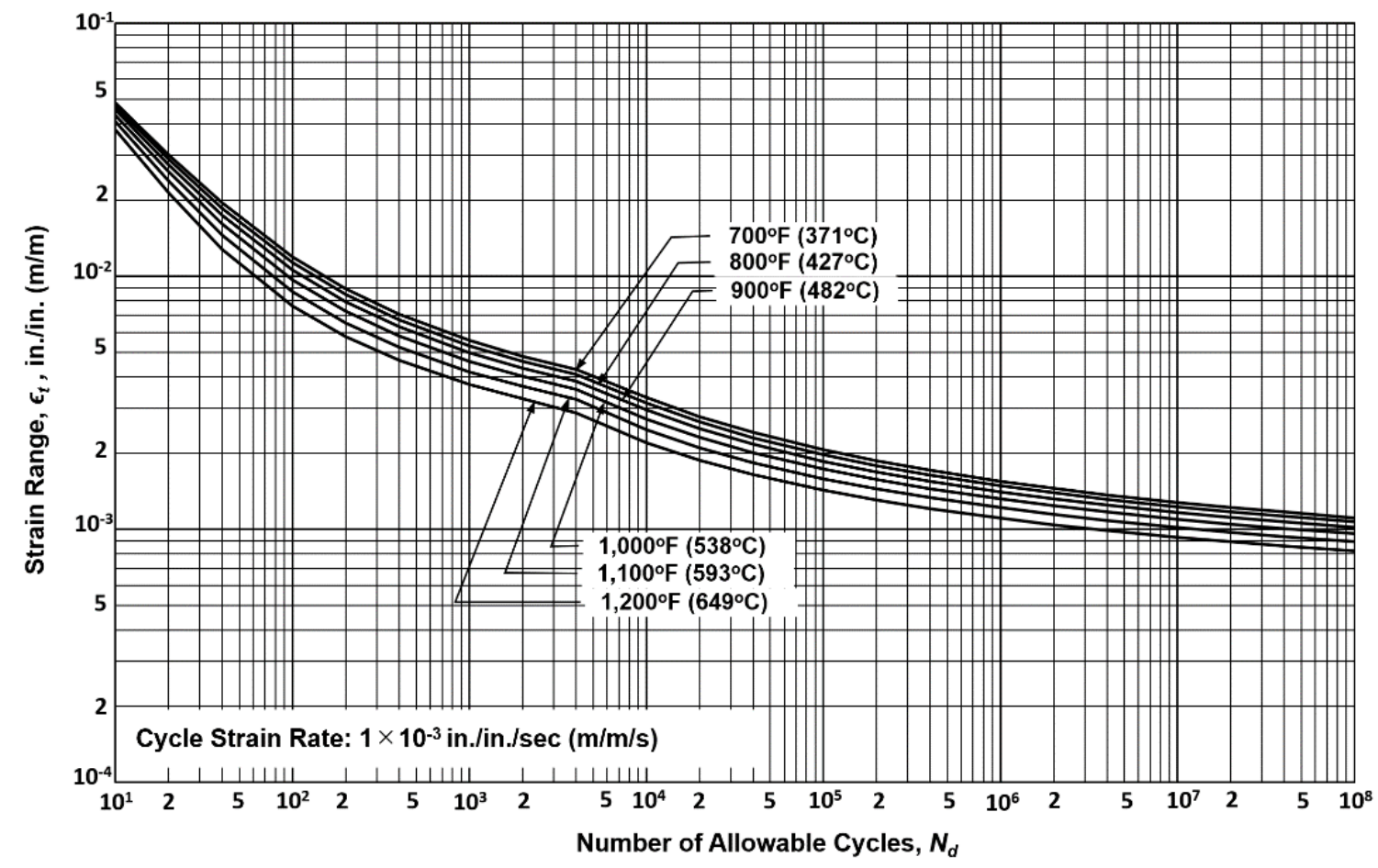

Fig. 2. Proposed temperature-dependent fatigue design curves for Gr. 91.

\section{PROGRESS IN DEVELOPMENT OF ALTERNATIVE CREEP-FATIGUE EVALUATION METHOD FOR GR. 91}

\subsection{INTEGRATED EPP+SMT CF EVALUATION METHODOLOGY}

The current ASME code rules for CF evaluation based on the damage diagram require the separate evaluation of creep damage and fatigue damage by placing a limit on the allowable combined damage, the damage diagram, based on the calculated individual damages. The uncertainties in the separate evaluation of the creep damage and fatigue damage from the test data lead to the use of overly conservative design factors in the current $\mathrm{CF}$ design procedure. The difficulties and the excessive conservatism in the damage diagram approach for $\mathrm{CF}$ evaluation are what led to the development of this alternative $\mathrm{CF}$ evaluation methodology, i.e., the integrated EPP analysis and SMT design methodology. The goal of this integrated EPP-SMT methodology is to maximize the advantages of both EPP methods and the SMT CF evaluation approach, which avoids the separate evaluation of creep and fatigue damages, eliminates the requirement for stress classification in current methods, and greatly simplifies the evaluation of elevated-temperature cyclic service.

The development of an SMT-based design curve requires a significant amount of SMT test data. Experimentally, SMT key feature CF testing has been fully developed and successfully tested for Alloy 617, SS 316H, SS 304H, and Gr. 91 (Wang et al. 2013, 2014, 2015, 2016a, 2017a, 2017b). The testing of the SMT key feature CF test articles was designed to evaluate the effects of elastic follow-up, stress concentration, primary load, strain range, loading rate, test temperature, and hold time. However, testing with the key feature SMT specimens requires specialized and costly instrumentation. Even more critical, the stress and strain redistribution for the SMT key feature test articles is complex; and it is difficult to 
extract information to support the development of modeling and analysis methods. To advance the design method, major effort was invested in FY 2018 for developing improved testing techniques to facilitate SMT-based CF testing. The new techniques, two-bar SMT (TBSMT) and single-bar SMT (SBSMT), both enable the use of standard CF specimens. The testing concept is explained in Wang et al. 2018a, 2018b, 2019a and 2019b. Experiments were designed and performed on Gr. 91 (heat 30176) using TBSMT and SBSMT. Both testing methods were verified, and they can support the extension of the integrated EPP+SMT design method to Gr. 91 (Wang et al. 2019b). Since the instrumentation for SBSMT is similar to that for standard CF tests and is much simply to apply, it was selected for all future SMT-based testing.

\subsection{SBSMT TEST RESULTS ON GR. 91 AT RELATIVELY LOW STRAIN RANGE}

The Gr. 91 specimen for SMT CF experiments used the standard ASTM CF specimen geometry, which has a $6.35 \mathrm{~mm}(0.25$ in.) gage diameter, as shown in Fig. 3.

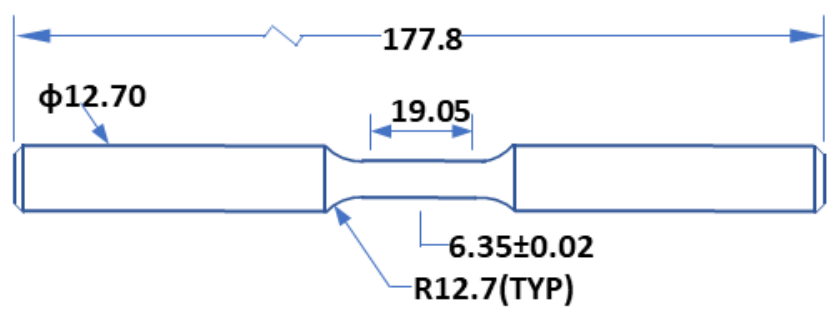

Fig. 3. Standard ASTM CF specimen geometry. Units are in millimeter.

The end-displacement loading profile was fully reversed with a strain ratio $\mathrm{R}$ of -1 . The specimen was loaded under the strain control mode with a hold time applied either at either peak tension or peak compression segment for $\mathrm{CF}$, or with no hold time for continuous cycling (pure fatigue.) The tests were automated through a LabView program.

SBSMT (test ID SB19) was carried out with a compression hold for $600 \mathrm{~s}$ to investigate the SMT CF behavior at relatively a low strain range for Gr. 91 (heat number 30176) at a nominal strain rate of $1 \mathrm{E}-3 / \mathrm{s}$ at $650^{\circ} \mathrm{C}$. The initial stable strain range was $0.3 \%$.

The elastic follow-up factor evaluated as a function of applied cycles is presented in Fig. 4. The elastic follow-up factor shows a relatively constant value of $1.98 \pm 0.13$ during the entire SBSMT. Note that the elastic follow-up factor was measured based on the tangential slope. The evolutions of strain range, maximum/minimum stresses, and representative hysteresis loops are presented in Fig. 5. The measured strain range gradually increased from an initial value of $0.3 \%$ to about $0.355 \%$ at failure initiation around 2511 cycles, then increased rapidly to $0.44 \%$ upon failure at 2719 cycles.

The development of maximum/minimum stresses in Fig. 5b is consistent with the evolution of the strain range when the applied cycles were increased; i.e., the rapid decrease in maximum stresses beyond failure initiation coincides with the rapid increase of the measured strain range. The changes in minimum stresses are not significant compared with those in the maximum stresses.

The representative hysteresis loops presented in Fig. 5c show parallel stress relaxation for those cycles, which is consistent with the observed relatively constant values of the elastic follow-up factor. 


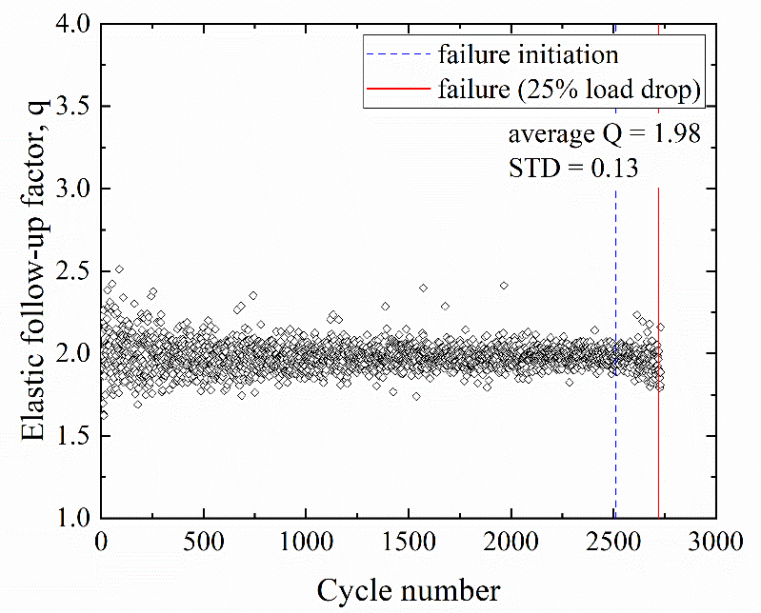

Fig. 4. Elastic follow-up factor as a function of applied cycle for Gr. 91 Gr. 91 SBSMT SB19

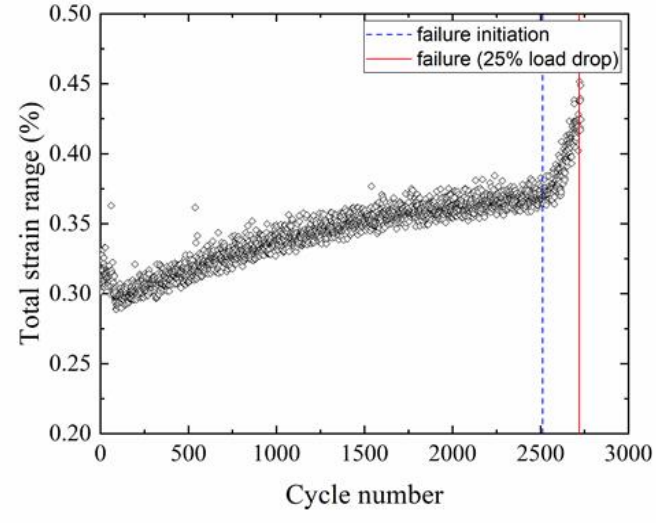

(a)

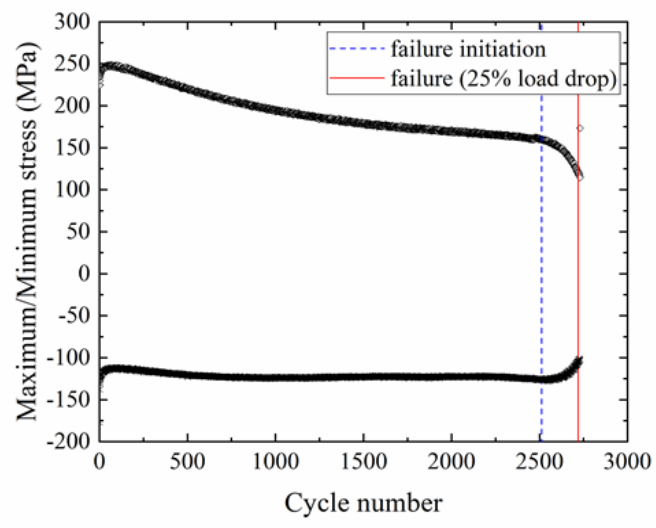

(b)

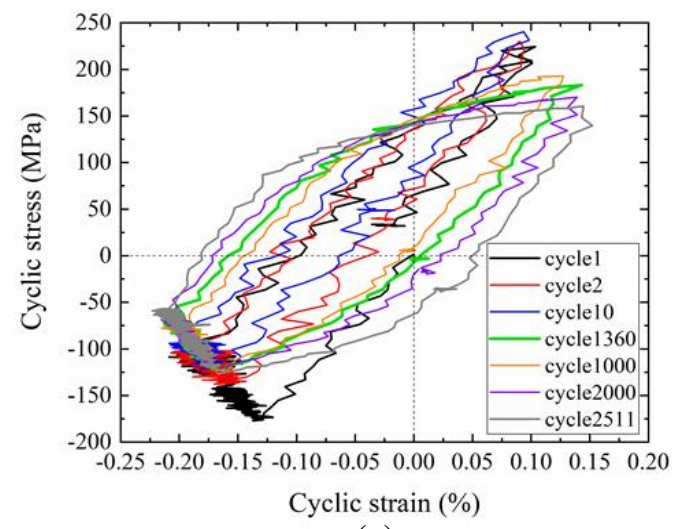

(c)

Fig. 5. Evolution of (a) strain range and (b) maximum and minimum stresses as a function of applied cycles, and (c) representative hysteresis loops for Gr. 91 SBSMT SB19. 
The stress relaxation curves of representative cycles during the compression-hold segment are compared in Fig. 6. In general, the stresses rapidly decrease during the initial $60 \mathrm{~s}$ of the compression-hold and slow down for the remaining time of the compression-hold for this test temperature. In order to quantitively analyze the stress relaxation behavior during the compression-holding, the stresses at the beginning and the end of the holding segment were extracted from the test data, and they are compared as a function of applied cycles in Fig. 6b. The ratio of these two stresses is also calculated and presented in Fig. 6c. The degree of stress relaxation is significant for the initial cycles and is gradually slowed down when additional cycles were applied, and the reduction in the degree of the relaxation seems to be linearly related to the applied cycles.

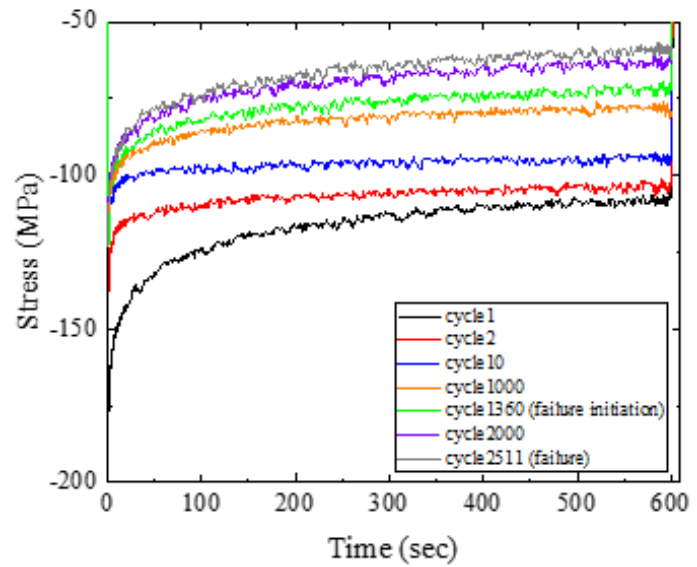

(a)

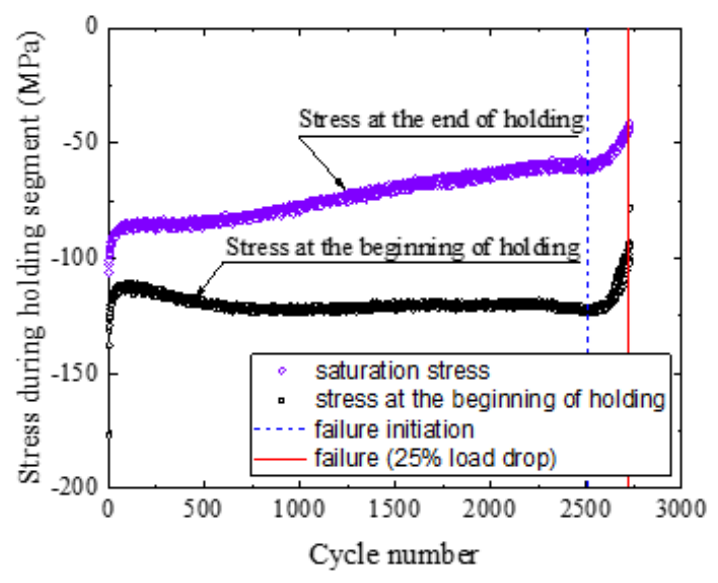

(b)

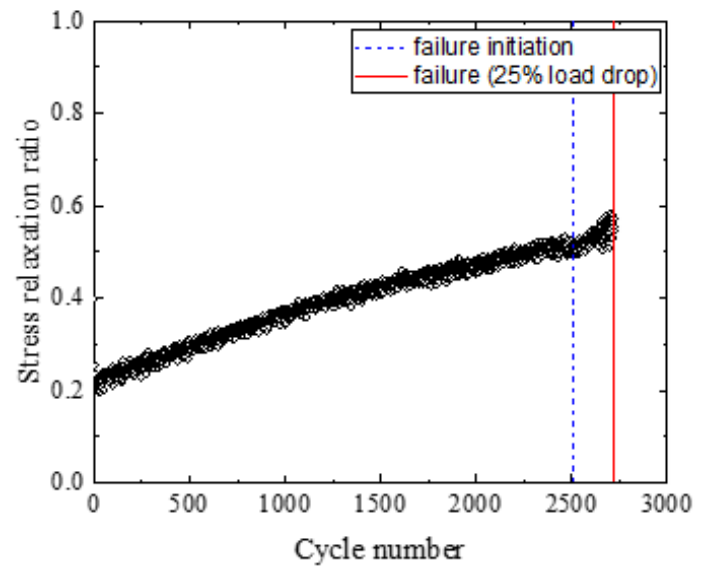

(c)

Fig. 6. Stress relaxation behavior during compression holding segment. (a) Stress relaxation curves of representative cycles, (b) saturation stress, and (c) stress relaxation ratio for Gr. 91 SBSMT SB19

Additional parameters are identified on a schematic hysteresis loop shown in Fig. 7. In this case, the loading strain range, $\Delta \varepsilon_{\text {loading }}$, and the total strain range, $\Delta \varepsilon$, are defined as

$$
\begin{aligned}
& \Delta \varepsilon_{\text {loading }}=\varepsilon_{1}-\varepsilon_{2} \\
& \Delta \varepsilon=\varepsilon_{1}-\varepsilon_{3}
\end{aligned}
$$


The extra creep strain accumulated during the relaxation segment due to elastic follow-up effect is the difference between the total strain range, $\Delta \varepsilon_{\text {total }}$, and $\Delta \varepsilon_{\text {loading }}$; i.e.,

$$
\Delta \varepsilon_{\text {creep }}=\Delta \varepsilon_{\text {total }}-\Delta \varepsilon_{\text {loading }}=\varepsilon_{3}-\varepsilon_{2}
$$

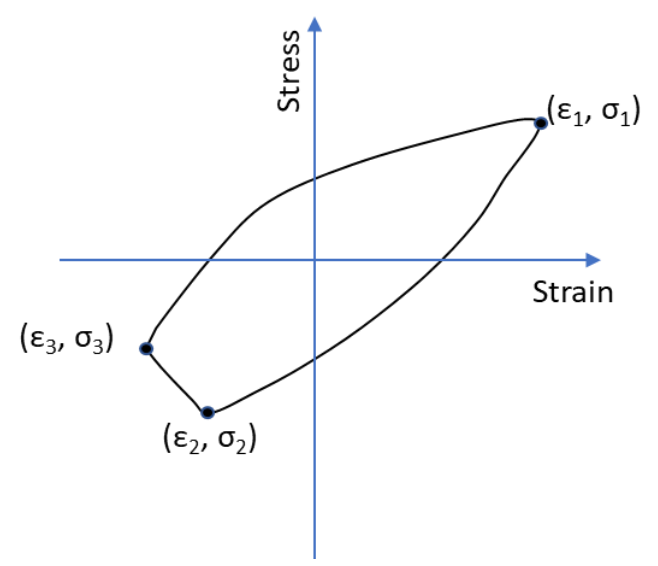

Fig. 7. Characteristics of the hysteresis loop of the SBSMT test.

The evolution of the loading strain range, $\Delta \varepsilon_{\text {loading }}$, measured from the loading and unloading segment and the creep strain range due to elastic follow-up, $\Delta \varepsilon_{\text {creep }}$, for SB19 are plotted in Fig. 8. Interestingly, the results show that the increase in the measured total strain range is mainly due to the increase in the loading strain range, and the increase in the creep strain is insignificant when additional cycles are applied.

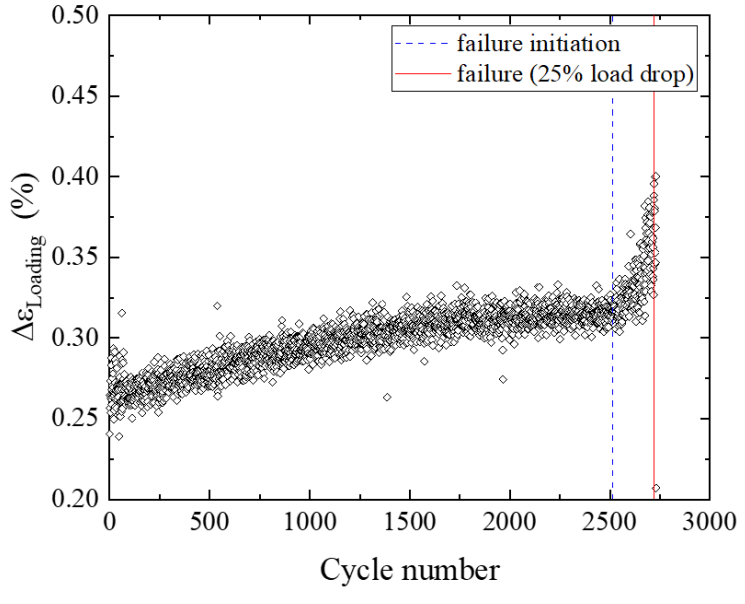

(a)

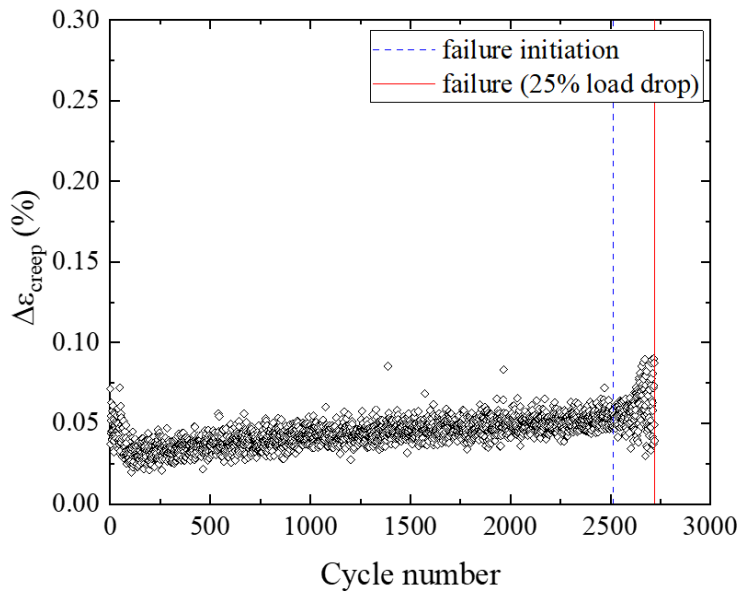

(b)

Fig. 8. Evolution of (a) loading strain range and (b) creep strain as a function of applied cycles for SB19 


\subsection{EFFECT OF HOLD TIME ON SMT CREEP-FATIGUE LIFE}

\subsubsection{Estimation of the Hold-Time Effect on Creep-Fatigue Cyclic Life}

Messner and Sham (2019) proposed a modified Coffin model to represent the hold-time effect for straincontrolled CF tests, expressed as

$$
N=N_{\text {fatigue }}\left(\frac{1}{q} \frac{\left(\frac{1}{1+t_{h}}\right)^{p}+D}{1+D}\right)
$$

where $N$ is the creep-fatigue cyclic life, $N_{\text {fatigue }}$ is the fatigue life (no holding), $q$ is the elastic follow-up factor, $t_{h}$ is the hold time in hrs, and $p$ and $D$ are fitting parameters from hold-time test data.

Standard fatigue and CF test data on Gr. 91 tabulated by Asayama and Tachibana (2009) were used to calibrate the fitting parameters. In this case, the elastic follow-up factor $q$ was equal to 1 . The pure fatigue best-fit curves from JSME were used to generate $N_{\text {fatigue }}$. The equation form was reported by Onizawa et al. (2013), and the fitting parameters are listed in Table 2.

Table 2. Parameters for the modified Coffin model for Gr. 91 at $600^{\circ} \mathrm{C}$

\begin{tabular}{c|c}
\hline Parameter & value \\
\hline$p$ & 25.5 \\
\hline$D$ & 1.14 \\
\hline
\end{tabular}

The experimental data from Asayama and Tachibana (2009) and the fatigue and CF best-fit curves based on the modified Coffin model are presented in Fig. 9a. The elastic follow-up effects on the CF life with $q=2$ and $q=3.5$ are presented in Fig. $9 \mathrm{~b}$ and c. The predicted reductions in CF life cycles at shorter hold times are plotted as Fig. 9d.

The major issue was that no data were available for strain ranges lower than $0.45 \%$. Therefore, the reduction of the CF life due to the hold-time effect from this analysis was basically assumed to be the same as that in the low cycle/high strain range region, and independent of the applied strain range. Although this assumption was not correct, the analysis provided baseline information on the test design to calibrate the hold-time effect. Fatigue and CF test lives were estimated at a small strain range of $0.3 \%$ and a strain rate of $2 \mathrm{E}-3 / \mathrm{s}$; the results are listed in Table 3. Based on this analysis, three test conditions were selected. The pure fatigue test would provide a baseline comparison of this specific heat of Gr. 91 material with the average best fit fatigue curve. A 60 s hold-time CF test will provide a failure data point in a reasonable time frame. And additional SBSMT tests with selected elastic follow-up factors with the same hold-time will be used to assess the elastic follow-up effect. 


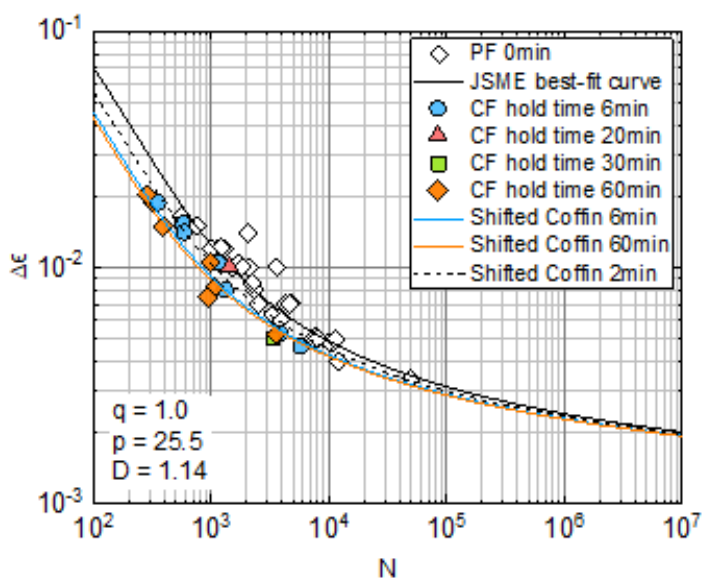

(a)

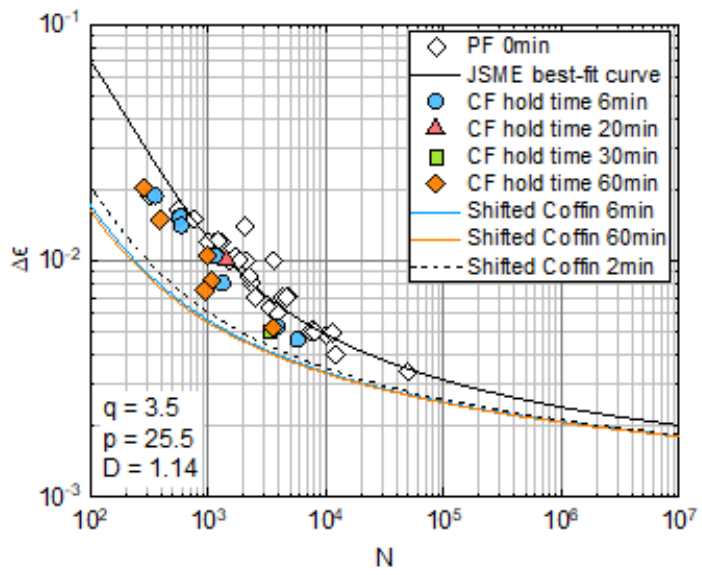

(c)

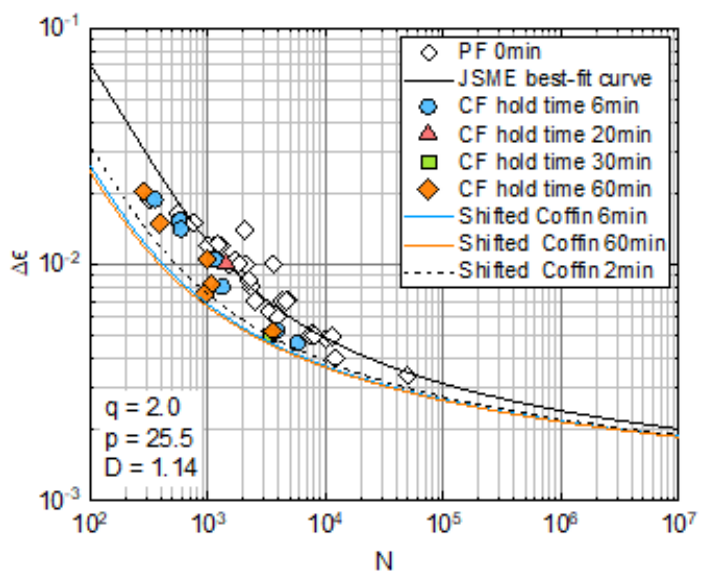

(b)

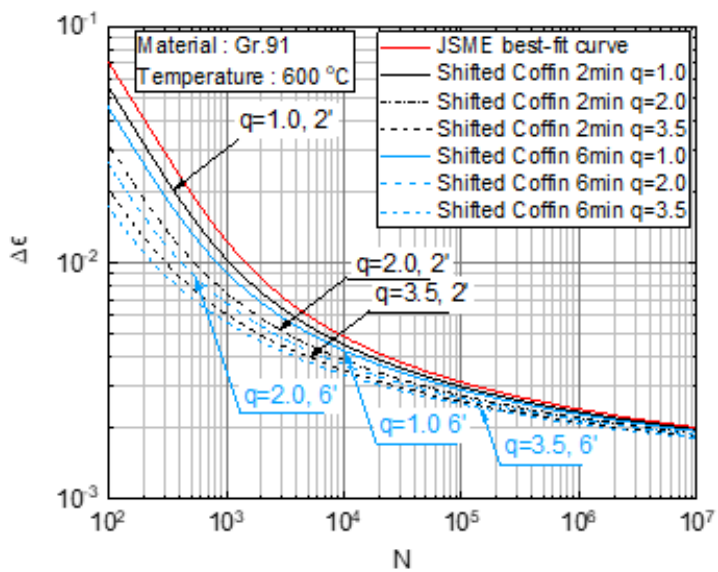

(d)

Fig. 9. Standard fatigue and creep-fatigue data and modified Coffin model for Gr. 91 at $600^{\circ} \mathrm{C}$ with (a) $q=$ 1.0, (b) $q=2.0$, (c) $q=3.5$ and (d) predicted short hold-time effect

Table 3. Estimation of fatigue and CF life and test duration using modified Coffin model for Gr. 91 at $0.3 \%$ strain range at $600^{\circ} \mathrm{C}$.

\begin{tabular}{c|c|c|c|c|c|c}
\hline $\begin{array}{c}\text { Temperature, } \\
{ }^{\mathbf{0}} \mathbf{C}\end{array}$ & $\begin{array}{c}\text { Strain } \\
\text { rate, /s }\end{array}$ & $\begin{array}{c}\text { Elastic } \\
\text { follow- } \\
\boldsymbol{u p}, \boldsymbol{q}\end{array}$ & $\begin{array}{c}\text { Strain } \\
\text { range, \% }\end{array}$ & $\begin{array}{c}\text { Hold } \\
\text { time, } \mathbf{s}\end{array}$ & Estimated life & $\begin{array}{c}\text { Estimated } \\
\text { duration, month }\end{array}$ \\
\hline 600 & $2 \mathrm{E}-3$ & 1.0 & 0.3 & 0 & $1.35 \mathrm{E}+05$ & 0.2 \\
& & & & 60 & $1.04 \mathrm{E}+05$ & 2.5 \\
& $2 \mathrm{E}-3$ & 2.0 & 0.3 & 0 & $6.37 \mathrm{E}+04$ & 4.3 \\
\hline 600 & & & & 60 & $5.19 \mathrm{E}+04$ & 1.3 \\
& $2 \mathrm{E}-3$ & 3.5 & 0.3 & 0 & 6.704 & 2.1 \\
\hline 600 & & & & 60 & $1.61 \mathrm{E}+05$ & 0.04 \\
& & & & 120 & $1.41 \mathrm{E}+05$ & 1.2 \\
\hline
\end{tabular}




\subsubsection{Testing to Evaluate Hold-Time Effect on Gr. 91 at Low Strain Ranges}

To perform a quantitative assessment of the hold-time effect on the CF life of Gr. 91, two tests were designed using standard fatigue and CF setups, i.e., the elastic follow-up factor was equal to 1 for these tests. These standard tests had a strain ration of $R=-1$ with a nominal strain rate of $2 \mathrm{E}-3 / \mathrm{s}$. The parameters used in the current test are presented in Table 4 . The nominal strain range was $0.3 \%$ and the test temperature was $600^{\circ} \mathrm{C}$.

Table 4. Testing parameters for evaluation of hold-time effect for Gr. 91 with an elastic follow-up factor of 1

\begin{tabular}{c|c|c|c|c}
\hline Test type & Test temperature & Strain range, $\Delta \boldsymbol{\varepsilon}$ & Hold time & R ratio \\
\hline Pure fatigue & $600^{\circ} \mathrm{C}$ & $0.3 \%$ & 0 & -1 \\
\hline Creep-fatigue & $600^{\circ} \mathrm{C}$ & $0.3 \%$ & $60 \mathrm{~s}$ & -1 \\
\hline
\end{tabular}

For the pure fatigue test, Fig. 10 shows the maximum/minimum stresses and the stress range as a function of the applied cycle. The Gr. 91 result showed a gradual decrease in the maximum stresses followed by a rapid decrease starting from 211,800 cycle, which is defined as fatigue failure initiation. The development of minimum stresses during the fatigue testing is similar to the development of the maximum stresses; that finding indicates the cyclic softening of Gr. 91 at $600^{\circ} \mathrm{C}$ and $0.3 \%$ strain range. Although a previous study at lower temperature of $566^{\circ} \mathrm{C}$ did not show significant cyclic softening when the strain range was less than $0.4 \%$ (Wang et al. 2018).

This pure fatigue test at $600^{\circ} \mathrm{C}$ had an average control strain range was $0.316 \%$, and the cycles to failure were 220,400 . The fatigue life is compared with the JSME best-fit average fatigue curve in Fig. 11, along with literature test data tabulated by Asayama and Tachibana (2009). The fatigue life is about twice of the average fatigue life estimated from the best fit fatigue curve, indicating the Gr. 91 used in this study had stronger than average fatigue resistance.

The CF testing with a peak compression hold time of $60 \mathrm{~s}$ is on-going. The test will continue and the cycles to failure will be used to assess the reduction of the cycle life due to the hold time.

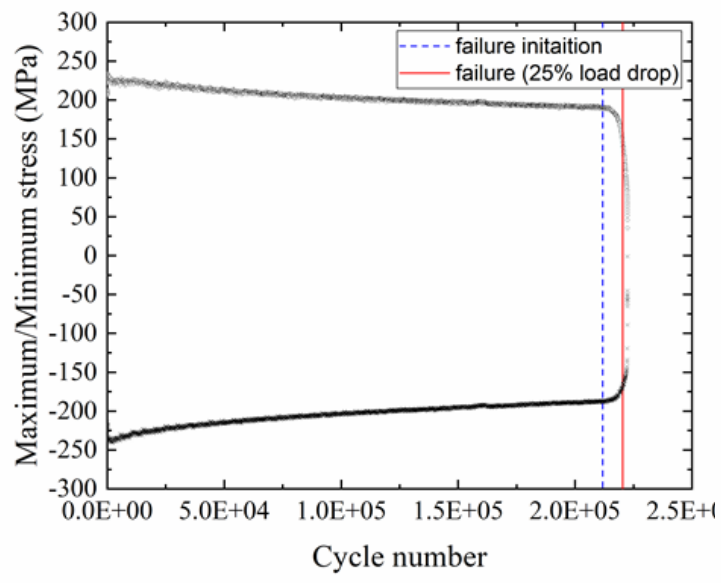

(a)

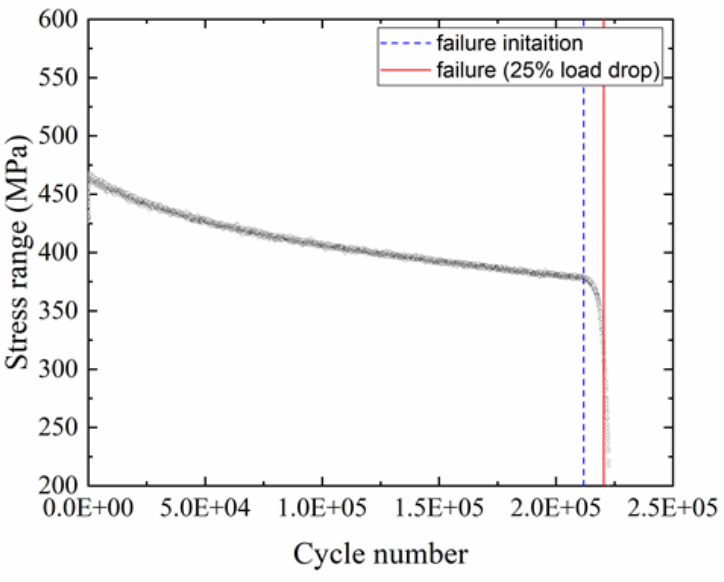

(b)

Fig. 10. Strain-controlled pure fatigue test on $\mathrm{Gr} .91$ at $600^{\circ} \mathrm{C}$ with (a) maximum and minimum stresses and (b) stress range as a function of applied cycles. 


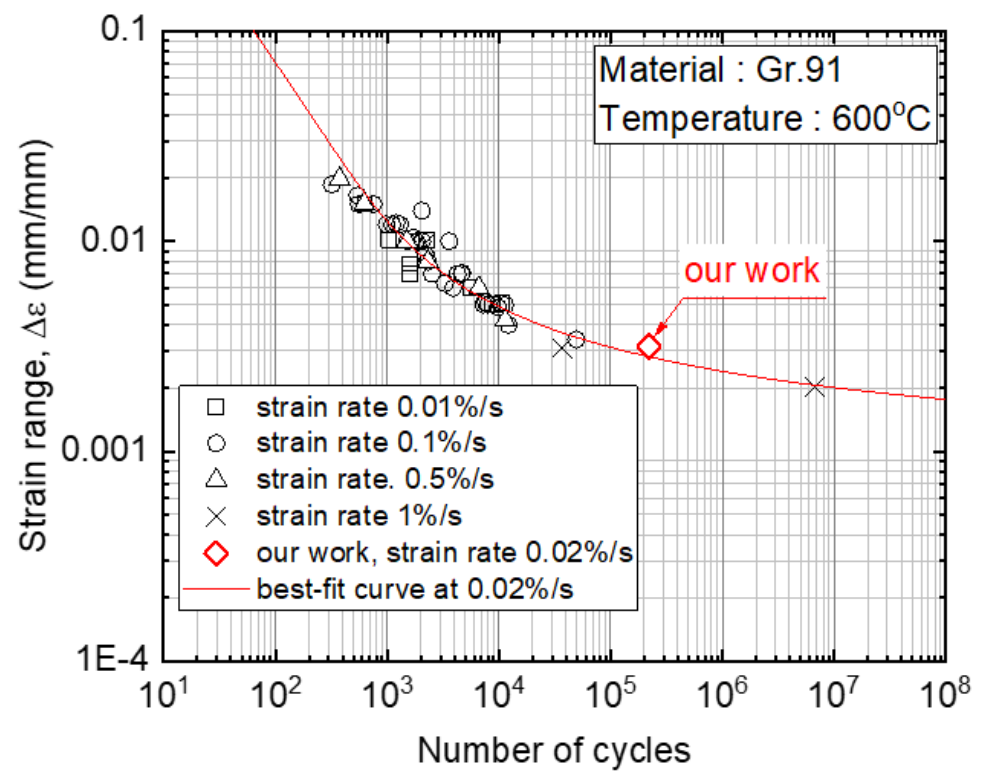

Fig. 11. Comparison of the strain-controlled fatigue test result with literature data and the JSME best-fit curve of Gr. 91 at $600^{\circ} \mathrm{C}$.

\subsubsection{SBSMT Hold-Time Testing with Large Elastic Follow-up Factor}

Two additional SBSMT experiments were performed at $650^{\circ} \mathrm{C}$ with a larger elastic follow-up factor of 12 at relatively small strain ranges. The stress range and strain range measured were compared with the previous test SB11 and the results are plotted in Fig. 12. The holding segments for these three tests were different: SB11 had a compression hold of $600 \mathrm{~s}$, SB12 had a tension hold of $180 \mathrm{~s}$, and SB13 had a compression hold of $180 \mathrm{~s}$. All three tests had the same nominal applied displacement and showed similar cyclic softening behavior. The measured initial stable strain ranges were slightly different, with $0.25 \%$ for SB11, $0.29 \%$ for SB12 and $0.28 \%$ for SB13. The increase in the measured strain range due to cyclic loading was evident and was consistent with the previous observations. The cycles to failure were 6200, 5050 and 5800, respectively. The difference in fatigue life due to tension or compression hold-time profiles was insignificant. Evaluating these failure data against the best-fit fatigue curves based on the measured initial strain range, it is found that the cycle life was about 30 to $40 \%$ of the fatigue with a $180 \mathrm{~s}$ hold time, and a $70 \%$ reduction with a $600 \mathrm{~s}$ hold at this test temperature of $650^{\circ} \mathrm{C}$. The test results will be used as supporting information in establishing the hold-time effect on SMT-based CF design curves. 


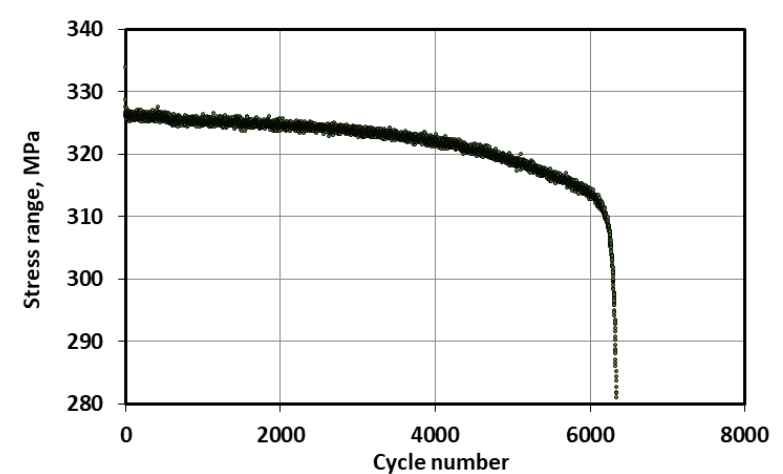

(a)

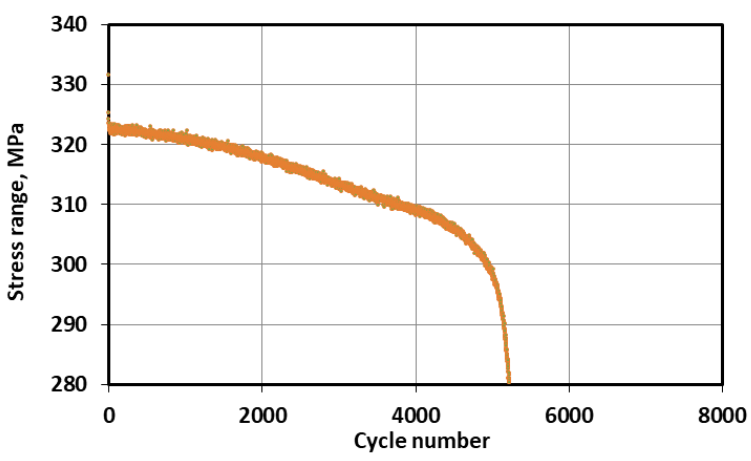

(b)

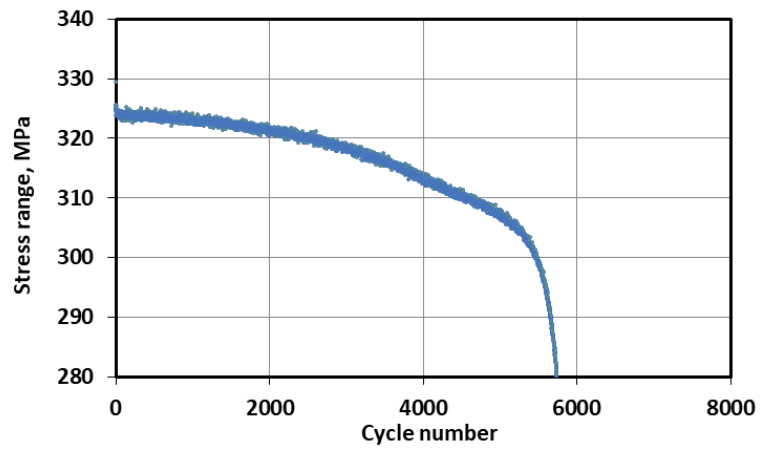

(c)

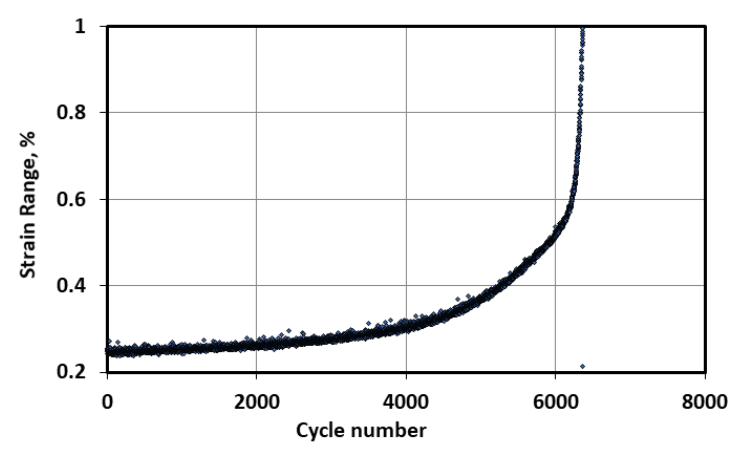

(d)

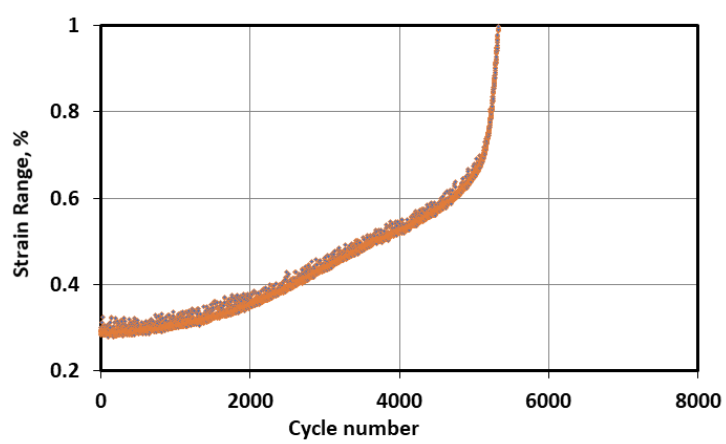

(e)

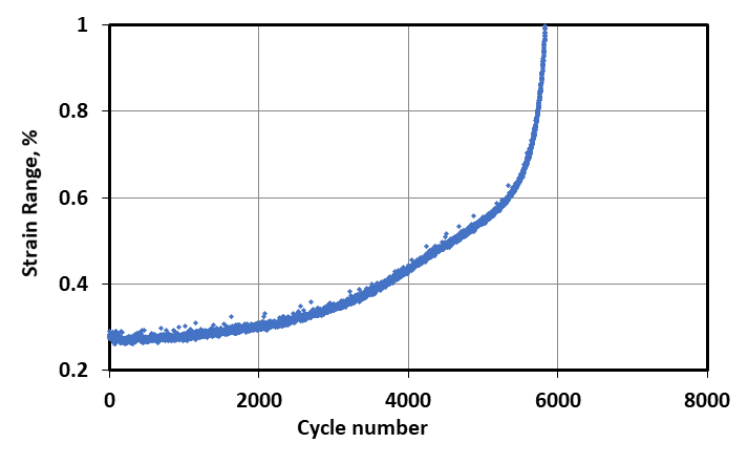

(f)

Fig. 12. Stress ranges and strain ranges as a function of applied cycles for SBSMT on Gr. 91 at $650^{\circ} \mathrm{C}$ with an elastic follow-up factor of 12, with (a, d) compression hold of $600 \mathrm{~s}$, (b, e) tension hold of $180 \mathrm{~s}$, and (c, f) compression hold of $180 \mathrm{~s}$

\subsection{EVALUATION OF PRIMARY LOAD EFFECT ON SMT CF LIFE FOR GR. 91}

The original SMT key-feature article testing provides critical information in developing the SMT-based CF evaluation methodology. Among the key feature article tests, pressurized tubular SMT was used to evaluate the effect of the primary load (Wang et al., 2019c). In the original SMT concept proposed by Jetter (1998), it was argued that the effects of sustained primary stress loading could be safely neglected because the local stress and strain levels for cyclic loading at peak stress locations were much higher than the allowable sustained primary stress levels. However, recent experimental results have shown that the 
SMT CF life was decreased when primary load was introduced to Alloy 617 SMT tests at a high temperature of $950^{\circ} \mathrm{C}$. This key assumption requires experimental verification for Gr. 91 . This task involves the design of experimentation for conducting SMT testing with internal pressurization and the subsequent testing of Gr. 91 under these loading conditions.

In the considerably simplified SBSMT method developed by Wang et al. 2019a, a standard-sized ASTM specimen design and slightly modified standard CF testing instrumentation were used to evaluate the effect of elastic follow-up. To take advantage of this new development in the SMT testing methods, it is planned to use the SBSMT technique and perform tests with internally pressurized tubular specimens. The purpose is to assess the effect of primary load limits on SMT CF life and its impact on the development of SMT based design curves for Gr. 91.

The new specimen design is shown in Fig. 13. The specimen has a total length of 8 in with a uniform gage section of 1.5 in. A picture of the assembled specimen is shown in Fig. 14.

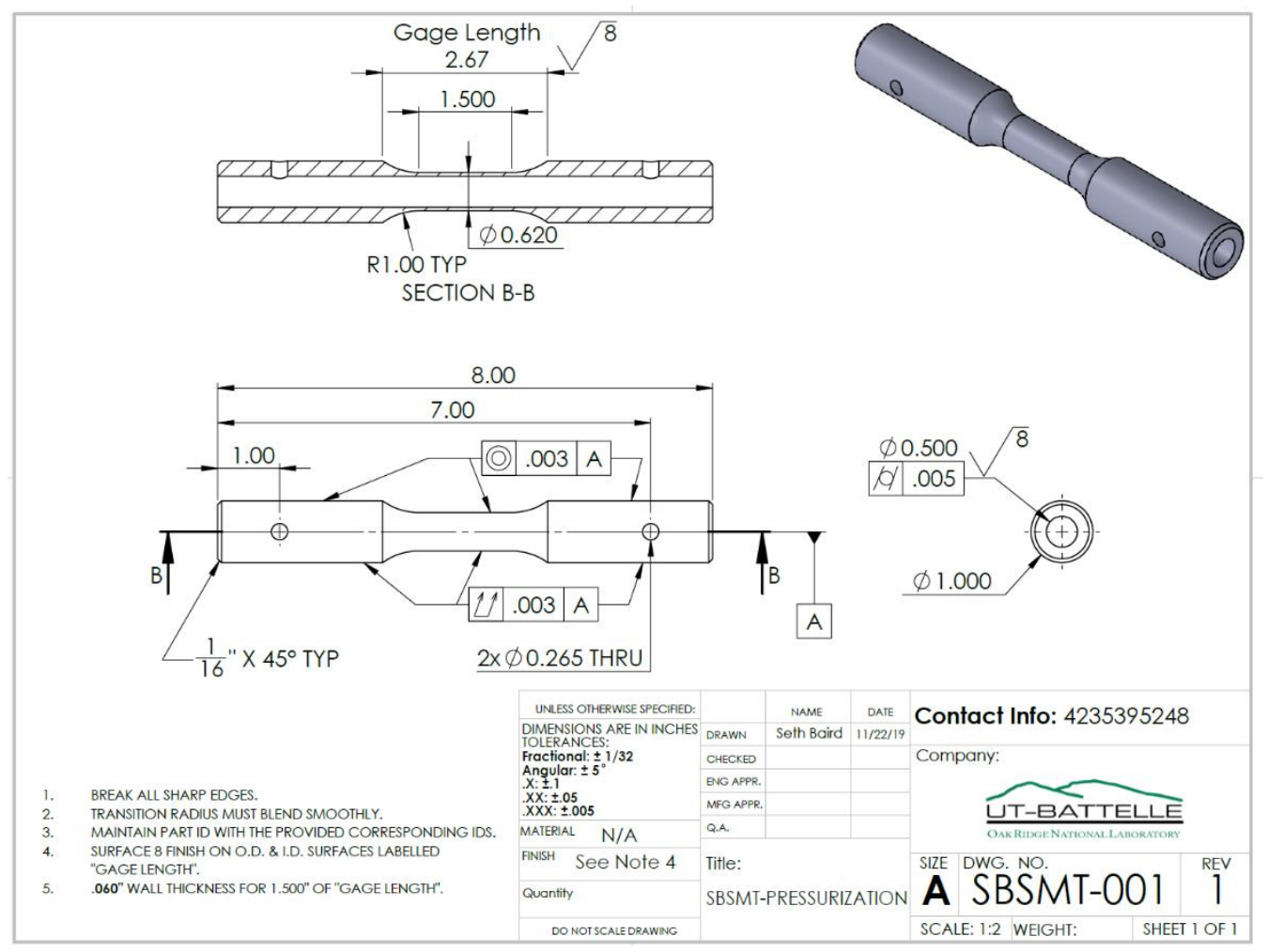

Fig. 13. Tubular SBSMT specimen geometry. Units are in inches.

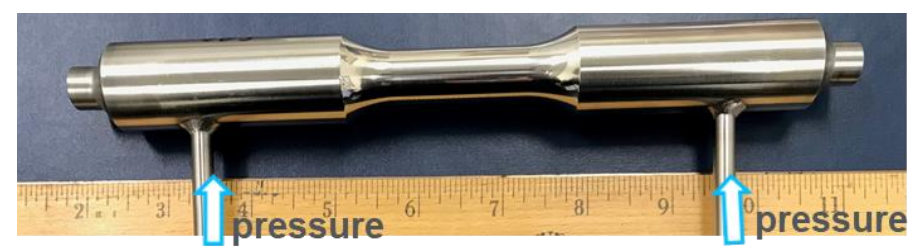

Fig. 14. Picture of the SBSMT specimen for evaluation of primary load effect 
The plan is to conduct SBSMT on these tubular specimens with an internal pressure-induced primary load and use the cycles to failure and strain range measurements in the gage section to assess the primary load effect on the SMT CF curves. The testing and evaluation are on-going, and this task is targeted to be completed by FY 2021.

\subsection{SUMMARY OF THE SMT RESULTS FOR GR. 91}

All the test results for Gr. 91 (heat 30176) using both TBSMT and SBSMT techniques are summarized in Table 5. The highlighted tests are new results presented in this report.

Table 5. Summary of SMT CF results on Gr. 91 at $650^{\circ} \mathrm{C}$ (heat 30176).

\begin{tabular}{l|c|c|c|c|c|c}
\hline Test ID & SMT test method & $\begin{array}{c}\text { Test } \\
\text { temperature, } \\
\mathbf{0}\end{array}$ & $\begin{array}{c}\text { Elastic } \\
\text { follow-up } \\
\text { factor, } \boldsymbol{q}\end{array}$ & $\begin{array}{c}\text { Initial stable } \\
\text { strain } \\
\text { range, } \boldsymbol{\%}\end{array}$ & Hold time*, s & $\begin{array}{c}\text { Cycles to } \\
\text { failure }\end{array}$ \\
\hline TB03 & $\begin{array}{c}\text { TBSMT with } \\
\text { room-temperature } \\
\text { (RT) driver bar }\end{array}$ & 650 & 3.5 & 0.30 & 600 & 2050 \\
\hline TB07 & $\begin{array}{c}\text { TBSMT with RT } \\
\text { driver bar }\end{array}$ & 650 & 4.1 & 0.53 & 600 & 750 \\
\hline TB08 & $\begin{array}{c}\text { TBSMT with RT } \\
\text { driver bar }\end{array}$ & 650 & 3.5 & 0.55 & 600 & 800 \\
\hline TB06 & $\begin{array}{c}\text { TBSMT with RT } \\
\text { driver bar }\end{array}$ & 650 & 4 & 0.90 & 600 & 170 \\
\hline TB10 & $\begin{array}{c}\text { TBSMT with } \\
\text { driver bar at } \\
\text { 650 }{ }^{\circ} \text { C }\end{array}$ & 650 & 2.1 to 4.7 & 0.55 & 600 & 480 \\
\hline SB05 & SBSMT & 650 & 3.8 & 0.54 & 600 & 680 \\
\hline SB09 & SBSMT & 650 & 12 & 0.70 & 600 & 250 \\
\hline SB10 & SBSMT & 650 & 12 & 0.62 & 600 & 330 \\
\hline SB11 & SBSMT & 650 & 12 & 0.25 & 600 & 6200 \\
\hline SB12 & SBSMT & 650 & 12 & 0.29 & 180 (Tension) & 5050 \\
\hline SB13 & SBSMT & 650 & 12 & 0.28 & 180 & 5800 \\
\hline SB19 & SBSMT & 650 & 1.98 & 0.31 & 600 & 2719 \\
\hline PF20 & Pure fatigue & 600 & 1 & 0.316 & N/A & 220,400 \\
\hline
\end{tabular}

*. Hold time was applied to the compressive peak strain unless otherwise specified.

\section{ADDITIONAL TESTING IN SUPPORT OF VERIFICATION OF GR. 91 CODE RULES}

The development of the code rules for the primary load check for Gr. 91 is on-going. Gr. 91 is a known cyclic softening material, and the primary load code case will have to account for its cyclic softening characteristics. The primary load code rules are being developed at Argonne National Laboratory, and the idea is to use the EPP method to conduct the global creep rupture check and use the simplified inelastic method (elastic-creep model) to conduct the local creep rupture check. Determining how to treat the local triaxial stress state in the analysis will require experimental validation. Plans are to conduct supporting 
creep tests on the specimens under various combinations of multi-axial stress states at ORNL, and to evaluate the stress measure that provides the best correlations with the creep rupture life of Gr. 91 .

A biaxial stress state will be introduced in tubular creep specimens by applying combinations of axial load to internal pressurization. The stresses introduced by various combinations of the internal pressure and the external axial load, either tensile or compressive, will allow various stress ratios to be developed in the specimen. For example, for the same effective von-Mises stress of $80 \mathrm{MPa}$, Table 6 shows the calculated internal pressure with hoop-to-axial stress ratios of -2 to 2 for a specimen geometry with internal diameter of $D=0.6$ in and wall thickness of $t=0.06 \mathrm{in}$. The axial stress, $\sigma_{a}$, is the sum of the stress introduced by the internal pressure, $p$, and the external axial load, $\sigma_{\text {a.external }}$, as

$$
\sigma_{a}=\frac{p * D}{t}+\sigma_{a . e x t e r n a l}
$$

The negative values in Table 6 require a compressive external axial load and the positive values require a tensile external axial load. Creep specimens with external axial loading capabilities are designed to perform the multi-axial stress state creep evaluations. The designed specimen geometry for pure internal pressure loading or external compressive axial load is shown in Fig. 15 and that for testing with external tensile axial load is shown in Fig. 16. A special fixture design for loading specimens in compression in a conventional creep frame is shown in Fig. 17, the test specimen will be placed in between the parallel compression plates. A series of test conditions will be selected, and the target is to produce short-term creep rupture data with multi-axial stress state.

Table 6. Designed stress state with effective von-Mises stress of 80 MPa (11.6 ksi)

\begin{tabular}{c|c|c|c|c}
\hline $\begin{array}{c}\text { Ratio of Hoop } \\
\text { stress to Axial } \\
\text { stress }\end{array}$ & $\begin{array}{c}\text { Internal Pressure, } \\
\text { ksi }\end{array}$ & $\begin{array}{c}\text { Hoop stress, } \\
\text { ksi }\end{array}$ & $\begin{array}{c}\text { Axial stress, } \\
\text { ksi }\end{array}$ & $\begin{array}{c}\text { External axial } \\
\text { load, ksi }\end{array}$ \\
\hline$-\mathbf{2}$ & 1.72 & 8.62 & -4.31 & -8.62 \\
\hline $\mathbf{- 1 . 5}$ & 1.58 & 7.91 & -5.27 & -9.22 \\
\hline $\mathbf{- 1}$ & 1.34 & 6.69 & -6.69 & -10.03 \\
\hline $\mathbf{- 0 . 5}$ & 0.88 & 4.41 & -8.83 & -11.03 \\
\hline $\mathbf{0}$ & 0.00 & 0.00 & 11.60 & 11.60 \\
\hline $\mathbf{0 . 5}$ & 1.28 & 6.38 & 12.76 & 9.57 \\
\hline $\mathbf{1}$ & 2.11 & 10.55 & 10.55 & 5.27 \\
\hline $\mathbf{1 . 5}$ & 2.38 & 11.88 & 7.92 & 1.98 \\
\hline $\mathbf{2}$ & 2.43 & 12.16 & 6.08 & 0.00 \\
\hline
\end{tabular}




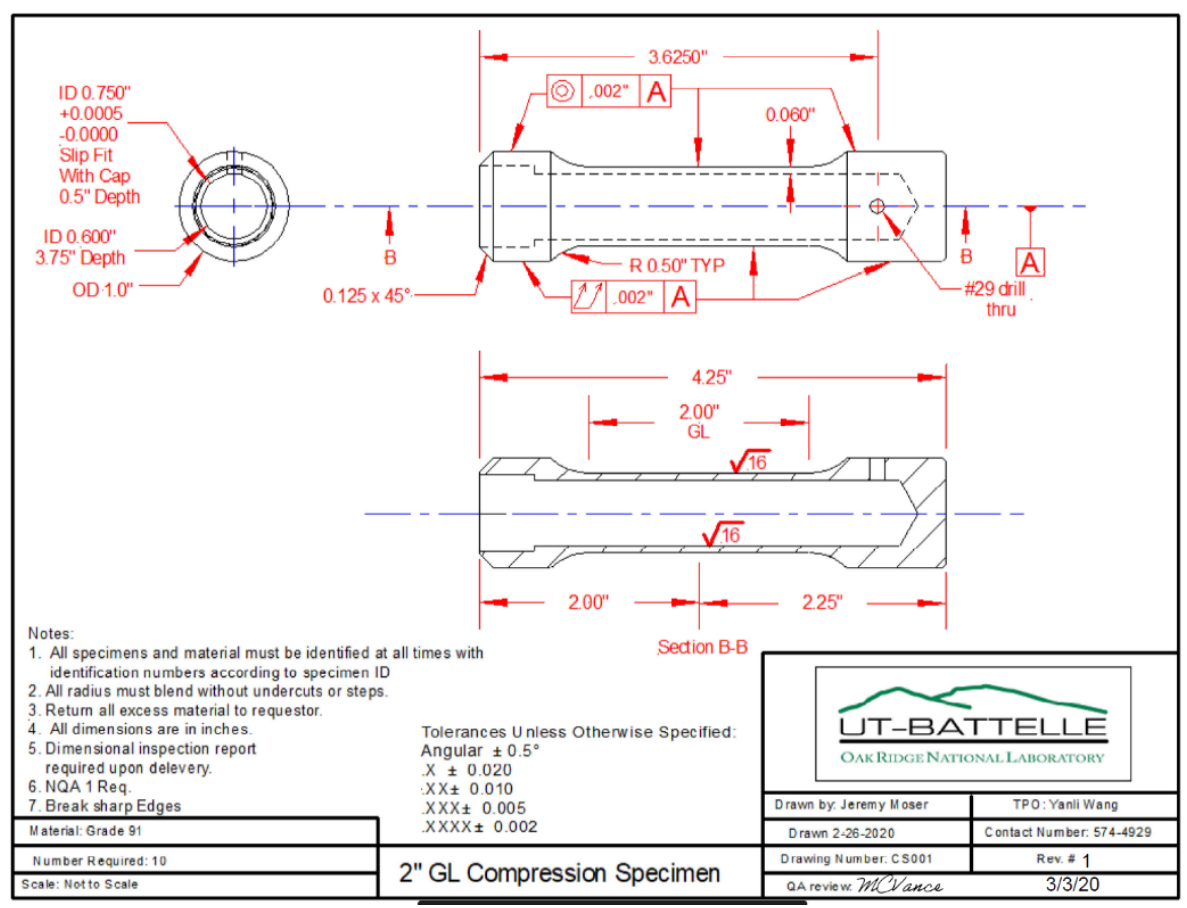

Fig. 15. Specimen design for creep testing with internal pressure and external axial compression loading.

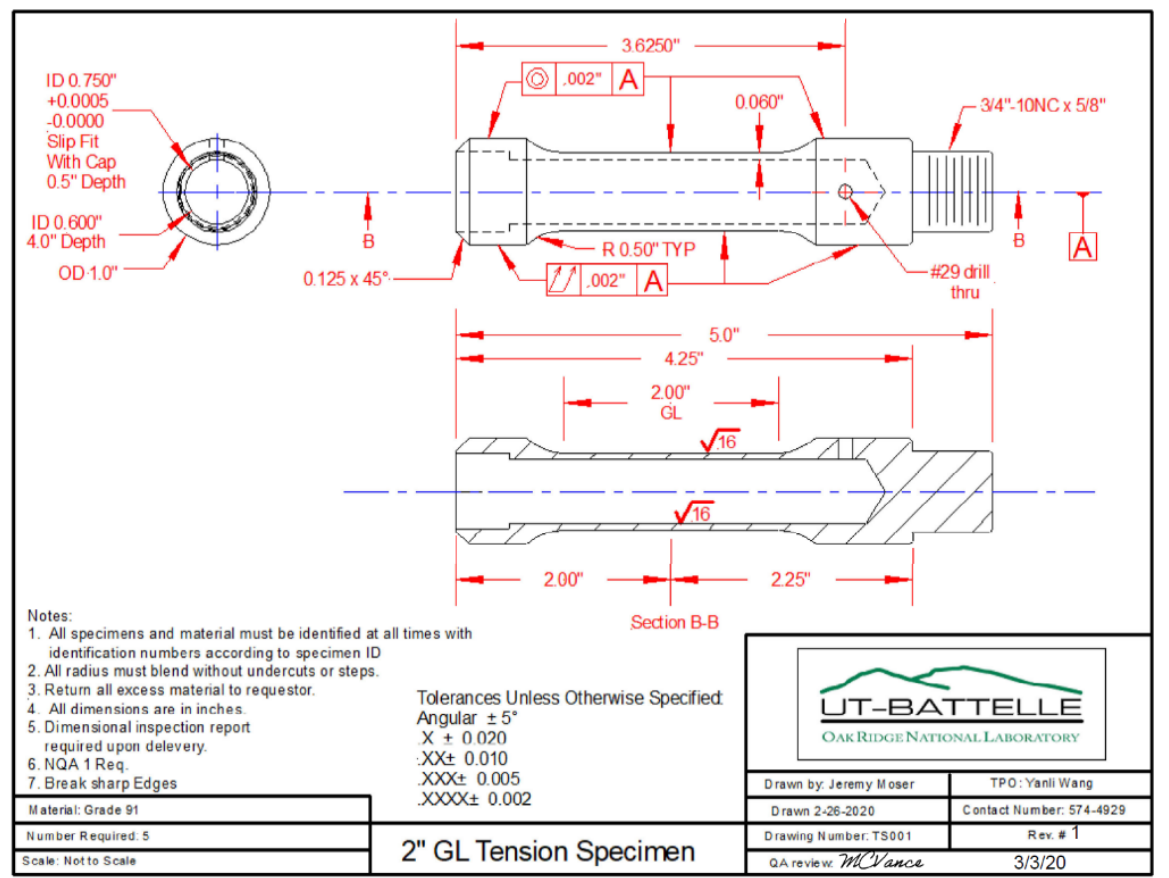

Fig. 16. Specimen design for creep testing with internal pressure and external axial tension loading. 


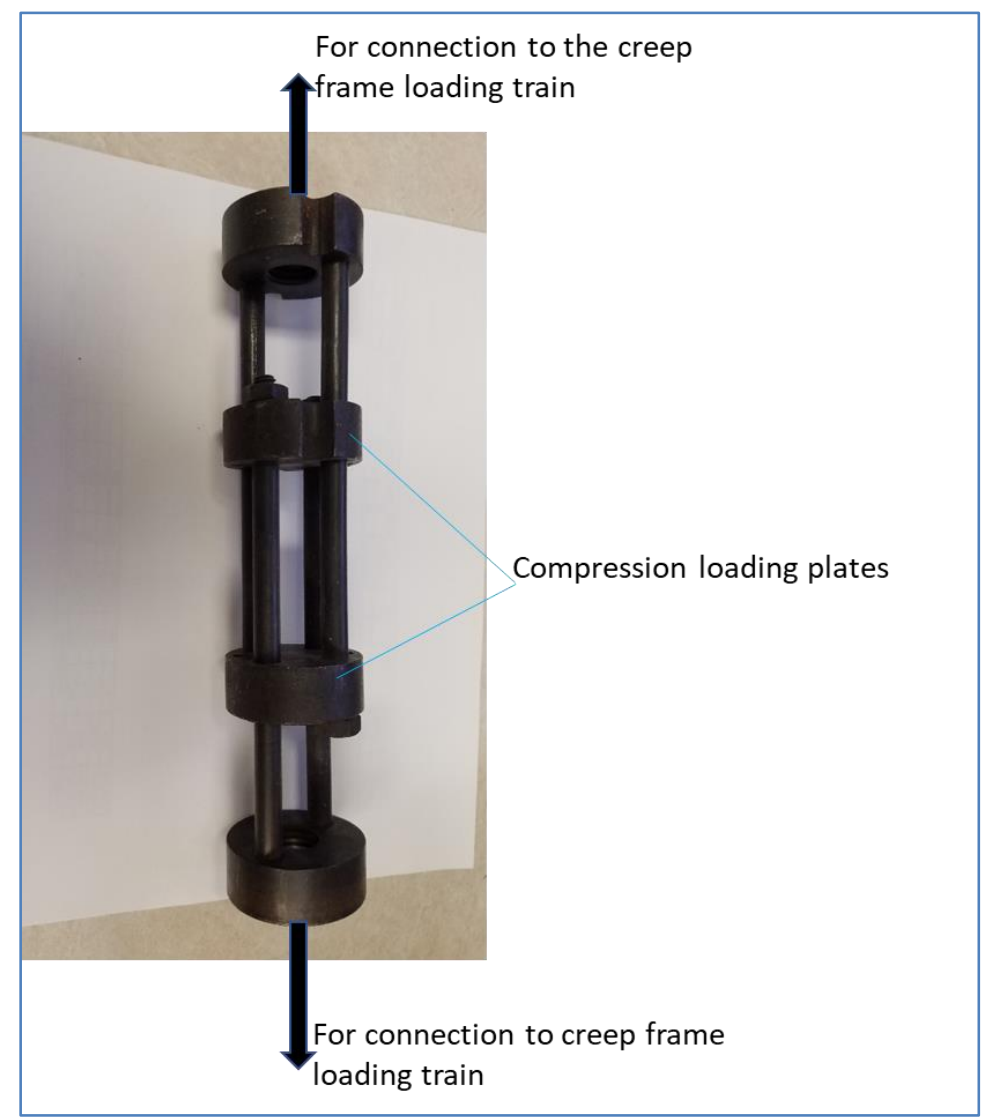

Fig. 17. Compression fixtures for loading in conventional creep frames.

At the time of writing this report, the specimens have been machined and the tests are being assembled. Photographs of the specimens machined out of Gr. 91 plate (heat 30176) are shown in Fig. 18. The testing will start in FY 2020 and continue in FY 2021. The main evaluation tests on multi-axial stress state effect will be completed by FY 2021.
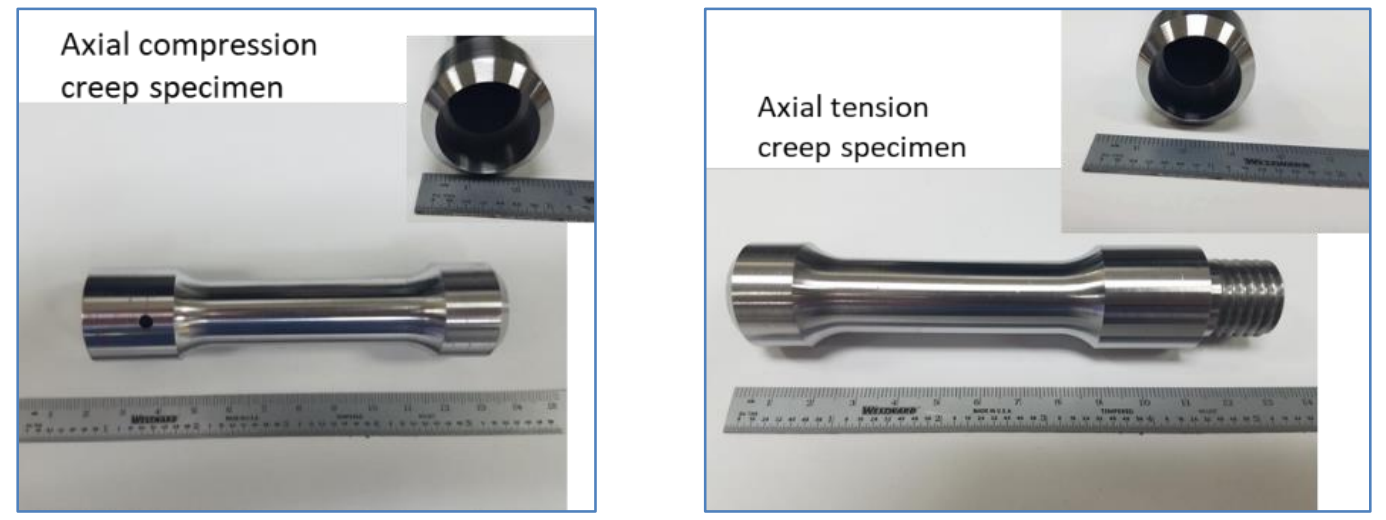

Fig. 18. Gr. 91 specimens for multi-axial stress creep testing. 


\section{SUMMARY}

The current ASME B\&PV Code Section III Division 5, has only one design fatigue curve for Gr. 91 at $540^{\circ} \mathrm{C}$ (or $1000^{\circ} \mathrm{F}$ ). Incorporation of the Gr. 91 temperature-dependent fatigue curves up to $650^{\circ} \mathrm{C}$ (or $1200^{\circ} \mathrm{F}$ ) in Section III Division 5 will support the design of Gr. 91 Class A components to higher operating temperatures. This report documents the incorporation of the Gr. 91 temperature-dependent fatigue curves in Division 5 and the associated major aspects brought up during the course of the ASME balloting process. The temperature-dependent fatigue design curves for Gr. 91 are expected to be incorporated in the 2021 edition of the ASME code.

Testing in support of the development of an integrated EPP plus SMT CF evaluation methodology continued. This integrated SMT-based CF evaluation methodology significantly simplifies the CF evaluation procedure and eliminates the over-conservatism of the existing CF damage diagram method. In FY 2020, analysis was performed to evaluate the hold-time effect on SMT CF life. Lack of test data at the high cycle and low strain range region is a major issue. Experiments were designed and initiated to fill the data gap and complete the development of SMT-based design curves for Gr. 91. Major on-going experiments and activities in support of the ASME code development and extension of Gr. 91 will be completed in FY 2021. 


\section{REFERENCES}

ASME Boiler and Pressure Vessel Code, Section III Division 5 Subsection HB Subpart B, American Society of Mechanical Engineers, New York, NY (2019 Edition).

Masanori Ando, ASME CW presentation on RC \#15-2731, Temperature dependent fatigue curves (Grade 91), WG-CFNC, Atlanta, 2018

JSME Codes for Nuclear Power Generation Facilities - Rules on Design and Construction for Nuclear Power Plants, Part II Fast Reactor Code, JSME S NC2-2016, 2016

Asayama, T and Tachibana, Y, (2009), Creep-fatigue and Existing Evaluation Procedures for Gr. 91 and Hastelloy XR, STP-NU-018, ASME Standards Technology, LLC, American Society of Mechanical Engineers, New York, NY.

Diercks, D.R. et. al., (1976) Statistical analysis and regression fit of elevated-temperature low-cycle fatigue data of type 304 stainless steel, ORNL-5150, Oak Ridge National Laboratory, Oak Ridge, TN, 1976.

DiStefano, J. R., et al., (1985), Summary of Modified 9Cr-1Mo Steel Development Program: 1975-1985, Technical Report No. ORNL-6303, Oak Ridge National Laboratory, Oak Ridge, TN.

Messner, M. C. and Sham, T.-L. (2019), Draft ASME Section III Division 5 Code Cases to extend EPP strain limits and creep-fatigue design methods to Grade 91, ANL-ART-165, Argonne National Laboratory. Lemont, IL.

Onizawa, T., Nagae, Y., Takaya, S. and Asayama, T., (2013), Development of 2012 Edition of JSME Code for Design and Construction of Fast Reactors (3) Development of Material Strength Standards for Mod.9Cr-1Mo Steel, PVP2013-97611, Proceedings of the 2013 ASME Pressure Vessels and Piping Conference.

Material test data of Mod.9Cr-1Mo steel (1), JAEA-Data/Code 2008-030, Japan Atomic Energy Agency, 2009.

Recommended test procedure for fatigue testing of metallic materials below the creep range REVISION 4 , Prepared by Subgroup on fatigue strength, ASME boiler and pressure vessel committee, The American Society of Mechanical Engineers.

R. I. Jetter, An Alternate Approach to Evaluation of Creep-Fatigue Damage for High Temperature Structural Design, PVP Vol. 5 Book No. H01146 - 1998, pp. 199-205, American Society of Mechanical Engineers, New York, NY, 1998.

Wang, Y., Sham, T.-L, and Jetter, R. I., (2013), Progress report on the development of test procedure for the two-bar thermal ratcheting experiment for Alloy 617, ORNL/TM-2013/318, Oak Ridge National Laboratory, Oak Ridge, TN.

Wang, Y., Jetter, R. I. and Sham, T.-L, (2014), Application of Combined Sustained and Cyclic Loading Test Results to Alloy 617 Elevated Temperature Design Criteria, ORNL/TM-2014/294, Oak Ridge National Laboratory, Oak Ridge, TN. 
Wang, Y., Jetter, R. I., Baird, S. T., Pu, C. and Sham, T.-L., (2015), Report on FY15 Two-Bar Thermal Ratcheting Test Results, ORNL/TM-2015/284, Oak Ridge National Laboratory, Oak Ridge, TN.

Wang, Y., Jetter, R. I., and Sham, T.-L., (2016a), FY16 Progress Report on Test Results In Support Of Integrated EPP and SMT Design Methods Development, ORNL/TM-2016/330, Oak Ridge National Laboratory, Oak Ridge, TN.

Wang, Y., Jetter, R. I., and Sham, T.-L., (2016b), Preliminary Test Results in Support of Integrated EPP and SMT Design Methods Development, ORNL/TM-2016/76, Oak Ridge National Laboratory, Oak Ridge, TN.

Wang, Y., Messner and Sham, T.-L., (2017a), FY17 Status Report on Testing Supporting the Inclusion of Grade 91 Steel as an Acceptable Material for Application of the EPP Methodology, ORNL/TM2017/388, Oak Ridge National Laboratory, Oak Ridge, TN.

Wang, Y., Jetter, R. I., Messner, M., Mohanty, S., and Sham, T.-L., (2017b), Combined Load and Displacement Controlled Testing to Support Development of Simplified Component Design Rules for Elevated Temperature Service, PVP2017-65455, Proceedings of the ASME 2017 Pressure Vessels and Piping Conference, American Society of Mechanical Engineers, New York, NY.

Wang, Y., Jetter, R. I., Messner, M., and Sham, T.-L., (2018a), Report on FY18 Testing Results in Support of Integrated EPP-SMT Design Methods Development, ORNL/TM-2018/887, Oak Ridge National Laboratory, Oak Ridge, TN.

Wang, Y., Messner, M., and Sham, T.-L., (2018b), Report on the FY18 Uniaxial Material Model Testing and Key Feature Test Articles Testing of Grade 91, ORNL/TM-2018/885, Oak Ridge National Laboratory, Oak Ridge, TN.

Wang, Y., Jetter, R. I., Messner, M., and Sham, T.-L., (2019a), Development of Simplified Model Test Method for Creep-fatigue Evaluation, PVP2019-93648, Proceedings of the ASME 2019 Pressure Vessels and Piping Conference, American Society of Mechanical Engineers, New York, NY.

Wang, Y., Jetter, R. I., Messner, M., and Sham, T.-L., (2019b), Report on FY19 Testing in Support of Integrated EPP-SMT Design Methods Development, ORNL/TM-2019/1224, Oak Ridge National Laboratory, Oak Ridge, TN.

Wang, Y., Jetter, R. and Sham, T.-L., (2019c), Effect of Internal Pressurization on the Creep-Fatigue Performance of Alloy 617 Based on Simplified Model Test Method, PVP2019-93650, Proceedings of the ASME 2019 Pressure Vessels and Piping Conference, American Society of Mechanical Engineers, New York, NY.

Wang, Y., M. D. McMurtrey, R. I. Jetter and T.-L. Sham, Evaluation of mean stress correction on fatigue curves of grade 91 and alloy 617 in ASME section III division 5, PVP2020- 21572, Proceedings of the ASME 2020 Pressure Vessels \& Piping Conference, American Society of Mechanical Engineers, New York, NY. 